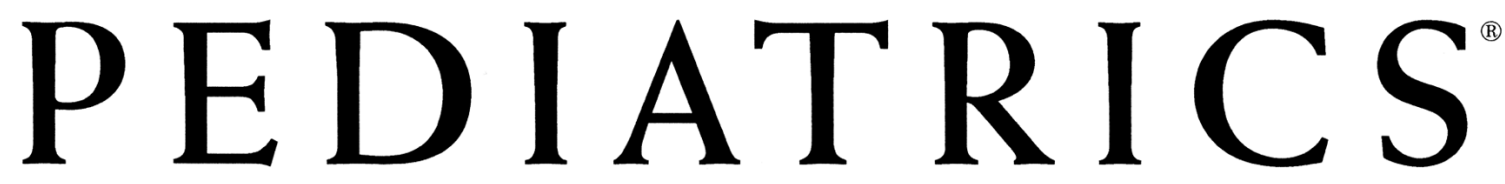

OFFICIAL JOURNAL OF THE AMERICAN ACADEMY OF PEDIATRICS

\title{
Guidelines for Implementation of Cystic Fibrosis Newborn Screening Programs: Cystic Fibrosis Foundation Workshop Report
}

Anne Marie Comeau, Frank J. Accurso, Terry B. White, Preston W. Campbell, III, Gary Hoffman, Richard B. Parad, Benjamin S. Wilfond, Margaret Rosenfeld, Marci K. Sontag, John Massie, Philip M. Farrell and Brian P. O'Sullivan

Pediatrics 2007;119;e495-e518

DOI: $10.1542 /$ peds.2006-1993

The online version of this article, along with updated information and services, is located on the World Wide Web at:

http://www.pediatrics.org/cgi/content/full/119/2/e495

PEDIATRICS is the official journal of the American Academy of Pediatrics. A monthly publication, it has been published continuously since 1948. PEDIATRICS is owned, published, and trademarked by the American Academy of Pediatrics, 141 Northwest Point Boulevard, Elk Grove Village, Illinois, 60007. Copyright ( 2007 by the American Academy of Pediatrics. All rights reserved. Print ISSN: 0031-4005. Online ISSN: 1098-4275.

\section{American Academy of Pediatrics}




\title{
Guidelines for Implementation of Cystic Fibrosis Newborn Screening Programs: Cystic Fibrosis Foundation Workshop Report
}

\author{
Anne Marie Comeau, PhDa, Frank J. Accurso, MDb, Terry B. White, PhDc, Preston W. Campbell, III, MDc, Gary Hoffman, BS ${ }^{d}$, \\ Richard B. Parad, MD, MPHa,e,f, Benjamin S. Wilfond, MDg,h, Margaret Rosenfeld, MD, MPHi, Marci K. Sontag, PhDj, \\ John Massie, MBBS, FRACP, PhDk, Philip M. Farrell, MD, PhD', Brian P. O'Sullivan, MDm
}

aNew England Newborn Screening Program and Department of Pediatrics, University of Massachusetts Medical School, Worcester, Massachusetts; ${ }^{\circ}$ Department of Pediatrics, Mike McMorris Cystic Fibrosis Research and Treatment Center, University of Colorado Health Sciences Center and Children's Hospital, Denver, Colorado; 'C Cystic Fibrosis Foundation, Bethesda, Maryland; dState Laboratory of Hygiene and 'Department of Pediatrics, University of Wisconsin, Madison, Wisconsin; eDepartment of Newborn Medicine, Brigham and Women's Hospital, Boston, Massachusetts; fDepartment of Newborn Medicine, Children's Hospital, Boston, Massachusetts; 9Social and Behavioral Research Branch, National Human Genome Research Institute, and hDepartment of Clinical Bioethics, Warren G. Magnuson Clinical Center, National Institutes of Health, Bethesda, Maryland; 'Department of Pediatrics, University of Washington School of Medicine, Seattle, Washington; iDepartment of Preventive Medicine, University of Colorado Health Sciences Center, Denver, Colorado; ' Department of Respiratory Medicine, Royal Children's Hospital, Melbourne, Australia; mDepartment of Pediatrics, University of Massachusetts Medical Center, Worcester, Massachusetts

The authors have indicated they have no financial relationships relevant to this article to disclose.

\section{ABSTRACT}

Newborn screening for cystic fibrosis offers the opportunity for early intervention and improved outcomes. This summary, resulting from a workshop sponsored by the Cystic Fibrosis Foundation to facilitate implementation of widespread high quality cystic fibrosis newborn screening, outlines the steps necessary for success based on the experience of existing programs. Planning should begin with a workgroup composed of those who will be responsible for the success of the local program, typically including the state newborn screening program director and cystic fibrosis care center directors. The workgroup must develop a screening algorithm based on program resources and goals including mechanisms available for sample collection, regional demographics, the spectrum of cystic fibrosis disease to be detected, and acceptable failure rates of the screen. The workgroup must also ensure that all necessary guidelines and resources for screening, diagnosis, and care be in place prior to cystic fibrosis newborn screening implementation. These include educational materials for parents and primary care providers; systems for screening and for providing diagnostic testing and counseling for screen-positive infants and their families; and protocols for care of this unique population. This summary explores the benefits and risks of various screening algorithms, including complex situations that can occur involving unclear diagnostic results, and provides guidelines and sample materials for state newborn screening programs to develop and implement high quality screening for cystic fibrosis.

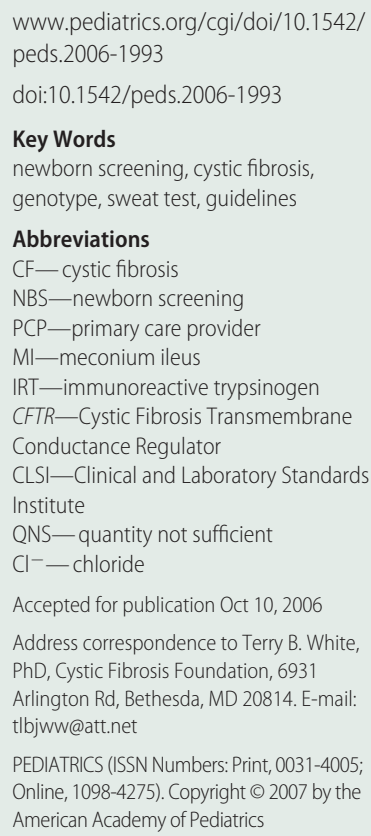


C YSTIC FIBROSIS (CF) is one of the most common life-shortening genetic diseases in the United States, affecting $\sim 30000$ children and young adults. Because early treatment improves outcome $e^{1-15}$ and the Centers for Disease Control and Prevention has stated that the addition of CF to state newborn screening (NBS) programs is justified, ${ }^{16}$ there has been increased interest in adding CF to state NBS programs. Individuals who are diagnosed with CF through NBS have improved nutritional status, ${ }^{17}$ better growth, ${ }^{14}$ and fewer hospitalizations, ${ }^{17-19}$ whereas a delayed diagnosis can result in significant cognitive dysfunction ${ }^{20}$ and nutritional failure. ${ }^{4}$ NBS has been shown to decrease the risk of life-threatening complications ${ }^{21}$ or death ${ }^{21,22}$ from CF in infancy or early childhood. Families of those with CF also benefit substantially from CF NBS, because they avoid the average 15-month delay between onset of symptoms and diagnosis ${ }^{17}$ along with the accompanying anxiety, frustration, and emotional distress. ${ }^{23}$ Costs of diagnosis, and possibly treatment (through fewer hospitalizations), are reduced by NBS. ${ }^{24}$ Finally, families can benefit from genetic counseling and identification of CF in older siblings as a result of NBS discovery of CF mutations.

Although CF NBS offers tremendous benefits for individuals diagnosed with CF and their families, it is accompanied by risks that also must be considered for optimal NBS-program design. These risks include the potential that infants with CF could have a delayed diagnosis by primary care providers (PCPs) who believe a negative NBS result is definitive, ${ }^{25}$ and that infants who are properly identified with CF by the screen could be exposed to health care-acquired infections during the diagnostic evaluation or early treatment. ${ }^{23}$ The families of infants with a positive screening result but not CF could experience unnecessary anxiety before the diagnostic result, 26,27 and doubts regarding the health of their normal infant may persist even afterward. ${ }^{28-31}$ Recognition of these risks is vital for optimal NBS-program design.

Components of a well-designed system necessary to address these issues successfully, as determined at a workshop held by the CF Foundation and attended by representatives from numerous state and international NBS programs, government agencies, and CF Foundation-accredited care centers (see "Acknowledgments"), are described here. The CF Foundation recommends implementation of CF screening in all newborns, with appropriate attention to these guidelines to reduce risks and maximize benefits for all participants

The goal of CF NBS programs should be to provide infants with CF an early opportunity to receive specialized medical care that will assist them in maintaining normal growth and development and delay pulmonary infection, with its associated subsequent decline of lung function. To that end, CF NBS programs should be integrated within established systems such as state-based
NBS programs to assure comprehensive education, testing, tracking, follow-up, and outcomes assessments. These NBS programs provide opportunity for early identification and treatment of infants who have disorders that otherwise would go unrecognized before irreversible clinical damage. This early opportunity is possible because indicators of disorders are detectable in the dried blood spot specimens that are collected universally from the newborn population at $\sim 2$ days of age during a presymptomatic period. NBS as a successful populationbased public health service began in the early 1960s when statewide screening for phenylketonuria was first implemented. ${ }^{32}$ Since that time, it has become a service offered by all states and most industrialized nations and includes screening for a variety of disorders.

NBS programs support sophisticated systems for coordination of their educational, laboratory, communications, and clinical services (ref 33 and Table 1). The particular disorders that are screened by each state's program are determined by state authority (state lists are available at http://genes-r-us.uthscsa.edu/nbsdisorders. htm). NBS programs can and do add new disorders, some of which are universally required and some of which are optional. The determination of whether CF is included in a state's NBS panel and, if so, whether it is included as a required (mandatory) or optional screen is in the purview of the state authority.

This document provides a guide to some initial processes involved in the implementation of CF NBS. The best way to conduct CF NBS in a particular region will depend on a number of complex issues. Systematic planning by the state and a CF NBS advisory body will maximize opportunity for success.

\section{SYSTEMATIC PLANNING FOR CF NBS}

To plan properly for CF NBS implementation, it is helpful to assemble a workgroup composed of those who will have operational responsibility for the local CF NBS program. Typically, this would include the state NBS program director and all of the center directors of the CF clinical care programs in the state. Some states may choose to have a larger working group that includes key support personnel such as CF clinic nurses, genetic counselors or directors of accredited sweat-testing facilities, and parents of children with CF. Initially, the CF NBS workgroup should focus discussions on the practical implications of various algorithms for screening and its follow-up to develop protocols and outline expected lines of responsibility (Table 2). As with other collaborations between multidisciplinary experts, it is likely that the CF NBS workgroup will function most smoothly when agreements about problematic issues (eg, costs, staffing, and authorship on publications that might be generated on the basis of data collected by the group) are in place. Ideally, the CF NBS workgroup would be an information resource and the operational arm of an 
Prescreen

Inform family (brochure)

Prenatal distribution

Neonatal distribution

Educate health care providers

Quality specimen collected

Quality specimen transported

Screen

Laboratory analysis

Quality control

Data integration/integrity

Postscreen contact with PCP

Every infant: notification

Positive screen result

Deliver report to PCP

Recommend next steps

Request repeat test; or

Recommend subspecialty referra

Track to assure next step

Negative screen result but clinical concern

Deliver report to inquirer

Educate inquirer on next steps

Prediagnostic test contact with parent

Positive screen result

Deliver report to parent

Educate parent

Schedule subspecialty referral

Negative screen result but clinical concern

Educate parent

Schedule subspecialty referral

Diagnostic evaluation

Evaluation

Interpretation

Postdiagnostic test

Report outcome to parent, PCP, and NBS

Positive diagnosis

Intake by subspecialty care

Education

Equivocal diagnosis

Follow-up plan

Education

Negative diagnosis

Education

Release

Quality control

Tracking

Outcomes assessment
Notice of CF NBS inclusion; grand rounds presentation; encourage consideration of CF diagnosis in screened children with symptoms

Blood spot testing algorithm chosen, considering:

Spectrum of CF disease to be identified

Resources available

Sweat-testing services

Genetic counseling (when applicable)

Integration with existing systems

Materials for $\mathrm{PCP}$ on risk

Materials for PCP on recommendations

Contact information for sweat testing and clinical evaluation materials to supplement report to subspecialist

Materials for PCP on risk and recommendations

Materials for PCP to use/hand to parent including description of sweat test

Specifics of CF center location; work to ensure rapid referral

Materials for PCP to use/hand to parent

Infection control

Define positive, negative, and borderline sweat-test results for NBS program

Case definition of $\mathrm{CF}$

Materials on positive, false-positive, and ambiguous results and mechanisms for reporting

Infection control and care guidelines

Infection control; follow-up and care

Genetic or posttest counseling

Regular meetings between NBS core program and CF care centers 


\begin{tabular}{|c|c|c|}
\hline Component & Action & Considerations \\
\hline \multirow[t]{9}{*}{ Screening algorithm } & Define goals for disease detection & Responsibility of NBS program \\
\hline & Select CF case definition relative to program goals & Responsibility of CF Workgroup \\
\hline & & $\begin{array}{l}\text { Does program aim to identify only infants with classic CF, } \\
\text { or those with mild/variable CF also? }\end{array}$ \\
\hline & Develop algorithm & Does NBS program collect 1 or 2 specimens? \\
\hline & IRT/IRT & $\begin{array}{c}\text { Projected numbers of true/false-positive results; true/ } \\
\text { false-negative results; need for sweat tests }\end{array}$ \\
\hline & IRT/DNA & $\begin{array}{l}\text { Projected numbers of true/false-positive results; true/ } \\
\text { false-negative results; CF carriers; need for sweat } \\
\text { tests, genetic counseling }\end{array}$ \\
\hline & $\Delta$ F508 only & What are the allele frequencies in population served? \\
\hline & Mutations associated with severe disease & \\
\hline & Mutations associated with severe or variable disease & \\
\hline \multicolumn{3}{|l|}{ Prescreen education } \\
\hline \multirow{4}{*}{$\begin{array}{l}\text { Lay community } \\
\text { Medical community }\end{array}$} & Develop resources for families & Responsibility of NBS program \\
\hline & & Responsibility of NBS program \\
\hline & Develop resources for PCPs & \\
\hline & Develop presentation for grand rounds & Presentation by members of CF workgroup \\
\hline \multirow{5}{*}{$\begin{array}{l}\text { Postscreen reporting } \\
\text { Positive result }\end{array}$} & & Responsibility of NBS program \\
\hline & Develop materials for reports & \\
\hline & $\begin{array}{l}\text { Develop checklists for telephone report and } \\
\text { recommendations to PCP }\end{array}$ & \\
\hline & Issue reports and recommendations & \\
\hline & Fax confirmation of details in writing & \\
\hline \multirow[t]{3}{*}{ Negative result } & Develop materials and fact sheets for report & Include written reminders \\
\hline & Issue reports & $\begin{array}{l}\text { Need to sweat test any infant with Ml or other clinical } \\
\text { signs of CF }\end{array}$ \\
\hline & $\begin{array}{l}\text { Recommend sweat test for any infant with CF-specific } \\
\text { clinical concern }\end{array}$ & Negative result does not rule out carrier status \\
\hline \multirow[t]{6}{*}{ Diagnostic evaluation } & Sweat test is gold standard & $\begin{array}{l}\text { All infants with a positive NBS result need sweat test } \\
\text { (regardless of parental carrier testing or NBS result) } \\
\text { All infants with clinical concern for CF should have sweat test }\end{array}$ \\
\hline & $\begin{array}{l}\text { Recommended site: CF care center with infection } \\
\text { controls }\end{array}$ & \\
\hline & Define positive, negative, and borderline values & \\
\hline & Genetic counseling & \\
\hline & On same day as sweat test, or & \\
\hline & As a follow-up appointment & \\
\hline \multirow[t]{4}{*}{$\begin{array}{l}\text { Quality control: tracking and } \\
\text { outcomes assessment }\end{array}$} & $\begin{array}{l}\text { All sweat-test results for NBS-positive infants should be } \\
\text { reported to the NBS program }\end{array}$ & $\begin{array}{l}\text { Centralized tracking by NBS program allows for quality } \\
\text { improvement, detection of unanticipated risks, and }\end{array}$ \\
\hline & $\begin{array}{l}\text { Extended DNA results should be reported to the NBS } \\
\text { program }\end{array}$ & $\begin{array}{l}\text { continuing modification and evaluation of the program; } \\
\text { CF clinician from care centers recommended to act as }\end{array}$ \\
\hline & $\begin{array}{l}\text { Any discordant result should be reported to NBS program (2 } \\
\text { severe mutations detected and negative sweat-test } \\
\text { result; discordant genotypes) }\end{array}$ & liaison with NBS program \\
\hline & $\begin{array}{l}\text { Any positive results of sweat testing resulting from clinical } \\
\text { concerns should be reported to NBS program (false- } \\
\text { negative results) }\end{array}$ & \\
\hline
\end{tabular}

overarching state NBS advisory committee, ${ }^{34}$ which should include representation from a wider variety of stakeholders including parent advocates, primary care professionals, staff from birth hospitals with obstetrical services, and insurers. All members of the CF NBS workgroup will have to become familiar with the various elements of a CF NBS program (Table 1). For each element, the workgroup must determine the extent to which (1) the basic standard of care is followed or exceeded, (2) compromises resulting from sociogeographic or socioeconomic considerations are incorporated, and (3) data are collected for quality improvement and research purposes.

Among the first tasks of the CF NBS workgroup should be to determine the spectrum of CF disease that the program will aim to identify. A successful CF NBS program must balance the desire to identify all infants with $\mathrm{CF}$, whose disease can vary from extremely mild to severe, with the realities of subjecting large portions of the population to diagnostic tests and limited resource 
availability. The CF NBS workgroup should determine the resources available and develop a screening algorithm that will optimize the use of these resources to identify those infants who are likely to receive the greatest benefit. Some states may choose to identify infants with all possible CF indications, because even mildly affected infants may experience life-threatening salt loss, ${ }^{35}$ although this is rare. Such decisions also increase the likelihood of identifying infants who either will not develop any CF symptoms or will only develop mild symptoms later in life. Other programs, with more limited resources, may choose to focus on a subset thought to have a prognosis of severe disease.

Finally, the CF NBS workgroup should ensure that all necessary guidelines for systems and care are in place before CF NBS implementation. A manuscript detailing the protocol for care of the newborn diagnosed with CF through NBS is under preparation by the CF Foundation.

\section{SPECIFICATIONS FOR SUCCESSFUL CF NBS PROGRAMS}

\section{Prescreen Education}

In addition to the standardized educational materials distributed by NBS programs to expectant parents and to parents immediately after the birth of their infant, the following types of CF-specific information should be developed or accessed for distribution:

- Notice to parents of availability of CF NBS: Typically coordinated by the state NBS program, this notice may be in the form of public service announcements, flyers, and educational materials distributed to prenatal services and educational brochures distributed to nurseries. Notices that reach parents prenatally may help them understand that prenatal and neonatal screening services are different and that both are available.

- Notice to pediatric health care providers of CF NBS: This task is usually coordinated by the state NBS program. A model notice, incorporating some educational material about CF, is shown in Appendix 1. Alternatively, notification may be in the form of a "legal notice" or public service announcement, especially if the state is adding several disorders to its screening program at once. Proper education of the primary care community is helpful in accomplishing the objectives of the CF NBS program and diminishing misunderstanding about the abilities and limits of the screen. Although state-of-the-art screening will identify $96 \%$ to $99 \%$ of CF-affected infants, ${ }^{36-38}$ false-negative results could cause a significantly delayed diagnosis because of complacency of the PCP, who may ignore clinical signs of the disease. ${ }^{25}$ Regardless of CF NBS results, diagnostic evaluation including sweat testing should be performed on any infant who evokes clin- ical concern, including all infants with meconium ileus (MI), and any infant whose parents are both carriers.

- Standardized presentations: These should be developed by the CF NBS workgroup to ensure that the information being provided in local educational seminars for physicians about CF NBS is accurate and representative of the protocol developed by the CF NBS workgroup. It is helpful when health care providers can be assured by the presenter that consultation with the CF NBS program is available in the event of a positive screening result, providing them with a support system.

These and other educational materials designed for CF NBS are available in those programs that have already initiated screening programs (see Table 3 and Appendices 1-3).

\section{Blood Spot Testing Algorithms for CF NBS}

All screening algorithms in current use in the United States rely on testing for immunoreactive trypsinogen (IRT) as the primary screen for CF. ${ }^{39}$ The presence of high levels of IRT, a pancreatic protein typically elevated in CF-affected infants, indicates the need for a second tier of testing, which determines the positive or negative outcome of the screen. The second-tier test may rely on IRT again or DNA testing; within these 2 categories, a variety of modifications are used ${ }^{40}$ because no single algorithm is perfect. For example, 2 different algorithms using DNA in the second tier could eventually identify a similar number of affected infants; however, one algorithm that tests for more Cystic Fibrosis Transmembrane Conductance Regulator (CFTR) mutations might result in quicker diagnosis and allow for earlier intervention, whereas the other might identify fewer carriers. In choosing an algorithm, consideration should be given to the goals of the program, the demographics of the population to be served, and the capacities of the screening laboratory, the clinical care programs, and the follow-up system. The incidence, prevalence, and (for algorithms using DNA) mutant allele distribution must be estimated to determine if facility and personnel needs resulting from a particular screening algorithm can be met. In considering these needs, it is useful to realize that an early diagnosis is important, but hours or days are not as critical in identification of CF as in that of several other standard newborn-screened disorders such as galactosemia or congenital adrenal hyperplasia.

\section{IRT Analysis: A Cautionary Note}

Because newborns with CF and MI may have low initial IRT values, ${ }^{41,42}$ resulting in a false-negative screen, all newborns with MI should have a sweat test regardless of NBS results. In contrast, infants who have significant perinatal stress or low Apgar scores or (as observed in 1 
1. The New England Regional Genetics Group has materials available for purchase at www.nergg.org/educationmaterial.php, including:

A listing of state genetic programs, comprehensive genetic counseling centers, and consumer support organizations

Optimizing Genetics Services in a Social, Ethical, and Policy Context, a booklet on a discussion of what consumers want, a set of detailed suggestions for responding to ethical problems in genetics, and a description of measures to optimize interactions between consumers and providers in clinical settings

Optimizing Genetic Services: Consumers Speak Out, a video that describes in personal terms the highlights of what both consumers and providers agreed should be part of optimal genetics services

2. The New South Wales Newborn Screening Programme has a parent/caregiver fact sheet available at www.chw.edu.au/prof/services/newborn/factsheets/ cystic_fibrosis.pdf

3. The Wisconsin NBS program has materials

Describing CF NBS for families (includes a video) (available at www.pediatrics.wisc.edu/patientcare/cf/newborn.html)

For the families of CF carriers (available at www.slh.wisc.edu/newborn/ brochures/b3p1.html)

4. The New York State Department of Health has materials for families and PCPs available at www.wadsworth.org/newborn/cfeducate.htm

5. The Nebraska NBS program offers

Materials for parents

CF fact sheet, available at www.hhs.state.ne.us/hew/fah/nsp/NewDocs/ ParentsPage/CFFactSheet.pdf

CF carrier fact sheet, available at www.hhs.state.ne.us/hew/fah/nsp/ NewDocs/ParentsPage/CFCarrierFactSheet.pdf

Initial positive result, available at www.hhs.state.ne.us/hew/fah/nsp/ NewDocs/ParentsPage/CFparentfactsheetInitialPositive.pdf

Initial inconclusive result: repeat recommended, available at www.hhs.state. ne.us/hew/fah/nsp/NewDocs/ParentsPage/CFparentfactsheetInitial Inconc.pdf

Initial inconclusive result: sweat test recommended, available at www.hhs. state.ne.us/hew/fah/nsp/NewDocs/ParentsPage/CFparentfactsheet InitiallnconcSweatTest.pdf

Repeat positive result, available at www.hhs.state.ne.us/hew/fah/nsp/New Docs/ParentsPage/CFparentfactsheetRepeatPositive.pdf

Repeat inconclusive result, available at www.hhs.state.ne.us/hew/fah/nsp/ NewDocs/ParentsPage/CFparentfactsheetRepeatInconc.pdf

Materials for PCPS

CF ACT sheet (recommended next steps when a positive or abnormal result is reported for one of your patients), available at www.hhs.state.ne.us/ hew/fah/nsp/NewDocs/MDPage/CFACTSheet.pdf

CF information (more specific disease information), available at www.hhs. state.ne.us/hew/fah/nsp/NewDocs/MDPage/CFINFOSheet.pdf

6. The Washington State NBS program offers materials for families and PCPs at www.doh.wa.gov/EHSPHL/PHL/Newborn/reports.htm\#CF

study) are black may display high IRT values, resulting in false-positive newborn screen results. ${ }^{36,43}$ The urgency associated with the report or follow-up protocol for infants with these risk factors may need modification.

\section{IRT/IRT Algorithms}

The choice of screening algorithms will be driven partially by whether the community NBS program routinely and universally collects 2 specimens or only a single specimen. If 2 specimens are universally collected, the community has the option to assay IRT in both primary and second-tier tests on specimens collected at $\sim 2$ days and then again at 14 days of age (IRT/IRT algorithm). Use of an IRT/IRT algorithm avoids the identification of large numbers of CF carriers from DNA analysis and the associated needs for genetic counseling. However, if only a single specimen is routinely collected, use of an IRT/IRT algorithm would require a specific request for a second sample and an acknowledgment that the first specimen screen result was positive. Because IRT levels decrease after the first weeks of life, the timing of sample collection is important and laboratory cutoffs for age-specific ranges must be established. In keeping with routine laboratory quality assurance, cutoff levels must be determined by each NBS laboratory to meet the desired sensitivity and specificity of the screen and should be evaluated periodically. Some laboratories may choose to use an absolute IRT value for a cutoff, whereas others may identify a percentage of the daily values as the cutoff. ${ }^{44}$ The latter method avoids the problem of seasonal variations in IRT values that may be caused by lability of the sample during shipment to the processing laboratory ${ }^{45}$ but may be more subject to variation as a result of daily population shifts.

\section{IRT/DNA Algorithms}

Some CF NBS programs may prefer to use a screen that includes DNA analysis. In fact, if the NBS program collects only a single specimen universally, then an algorithm with IRT as the primary screen followed by a DNA analysis on the specimens with elevated IRT concentrations (IRT/DNA algorithm) is typically chosen. The IRT cutoff that is selected to prompt DNA testing is a factor in producing false-positive and false-negative results that must be considered by the CF NBS workgroup.

Use of DNA analysis in the second tier of screening necessitates the selection of mutations in the CFTR gene for testing. A decision can be made to test for only the most common CFTR mutation, $\Delta \mathrm{F} 508$; for $\Delta \mathrm{F} 508$ and multiple mutations associated with severe disease; or for a panel of multiple mutations that includes some variants associated with mild or variable phenotypes. This decision must be based on a number of considerations, including those that are philosophical (the purpose of screening), scientific (current understanding of genotype-phenotype relationships), clinical utility (benefit to the infant and family), and practical (cost, system capacity for increased numbers of positive-screened infants).

The choice of whether to use a multiple-mutation panel or an assay for $\Delta \mathrm{F} 508$ alone is the first consideration. The frequency of $\Delta \mathrm{F} 508$ in the community will help determine the usefulness of a single-mutation assay in the second tier of the screen. In the Massachusetts CF NBS program, the use of a multiple-mutation panel (16-27 mutations) rather than just the single most common mutation increased the detection of affected infants by $50 \%$ and reduced the false-negative rate fourfold, although it also increased detection of carrier false-pos- 
itive results by $43 \% .{ }^{36}$ In other communities, the choice of using a single mutation in the second tier of the screen may adequately meet the needs set forth by that state's CF NBS workgroup.

The selection of mutations for a multiple-mutation panel can pose challenges, including:

- Reagent availability: Most NBS programs will use commercially available reagents, which have largely been developed for prenatal testing. However, these reagents are not completely compatible with CF NBS, because the goal of prenatal testing is detection of parent carriers rather than detecting infants with CF. Recently, commercial reagents that allow flexibility in selecting mutations for testing have come onto the market and will allow development of NBS- and population-specific instruments.

- CF genotype variation: Ideally, the mutation panel for screening should be based on the frequency of CF mutations present in the state CF population. A list of CF genotypes and frequencies observed in the CF care centers serving a community can be obtained from the CF Foundation. However, measurement of CF genotypes in nonnewborn clients of CF clinical care centers can only approximate the frequency in the newborn population. The validity of using these frequencies is limited as a result of issues that include ascertainment bias of CF in nonwhite populations, the extent of the CF population genotyped, population shifts, and the pattern of genotypes associated with diagnoses in symptomatic infants.

- Genotype/phenotype relationships: Some CFTR mutations, particularly those in classes IV (such as R117H) and $\mathrm{V}$ (such as A455E or $3849+10 \mathrm{~kb} \mathrm{C} \rightarrow \mathrm{T}$ or IVS8-5T) (see the Cystic Fibrosis Mutation Database [www.genet.sickkids.on.ca/cftr]) may be associated with milder phenotypes, ${ }^{46}$ and the benefit from screening algorithms that include these mutations has not been proven. Longitudinal epidemiologic data on individuals with classes IV and V mutations are quite limited, particularly with regard to lung disease, and few studies have included enough patients with a comprehensive analysis of outcome. ${ }^{47}$ Inclusion of DNA variants with undocumented pathogenicity in NBS mutation panels risks the detection of asymptomatic infants who may have late-onset mild disease for which the clinical utility of NBS is unproven and who may also incur insurance barriers. Projections of the rates of false-negative screens should be considered in relation to the specific objectives of the CF NBS program in making a decision to exclude these mutations from a screening panel. Use of these mutations in NBS is considered in more detail in "Special Considerations" below.

\section{Fail-safe for IRT/DNA Protocols}

Some NBS programs may choose to define the presence of ultrahigh IRT levels as a positive CF NBS result regardless of DNA-analysis results. The Massachusetts NBS protocol uses ultrahigh IRT values (eg, the top $0.2 \%$ of the population values, ${ }^{36}$ recently raised to the top $0.1 \%$ ) as a fail-safe protocol to identify infants with CF who have mutations that are not detected by the multiplemutation DNA panel. To increase specificity of this failsafe protocol, the IRT values of serial specimens are evaluated when infants have multiple samples submitted; if the value decreases to within reference levels within the first month of life, the infant is excluded from the recommendation for a sweat test. ${ }^{36}$ Because high IRT values are associated with multiple causes, some NBS programs may not consider ultrahigh IRT levels as a positive screen result. ${ }^{48}$ In California, the proposed CF NBS algorithm depends on a regionally customized DNA panel to maximize sensitivity and specificity of the newborn CF screen. In this algorithm, an IRT-level cutoff of $98.4 \%$ and at least 1 DNA mutation detected is projected to produce 661 sweat-test referrals, revealing 70 diagnosed cases of CF. Although including ultrahigh IRT levels with no DNA mutations in the positive screen results is projected to detect 2 additional infants with CF, it would also increase the number of sweat-test referrals by an additional 426 and, therefore, is not incorporated into the algorithm (M. Kharrazi, PhD, MPH, written communication, 2005). However, when the California algorithm was examined by retrospective application to the $110 \mathrm{CF}$-affected infants identified from a 4-year Massachusetts birth cohort, ${ }^{36} 12(11 \%$, including $4 \Delta \mathrm{F} 508$ homozygotes) would have been missed by the $98.4 \%$ IRT-level cutoff, and another $3(3 \%)$ would have been missed by the requirement for detection of at least 1 mutation (A.M.C., unpublished data). This would have been outside the $95 \%$ detection rate that the Massachusetts program set as its goal.

Each CF NBS workgroup must decide whether the community it represents will receive more benefit from such fail-safe protocols or from protocols that require development and maintenance of population-specific mutation panels for potentially changing populations.

\section{Summary}

States that wish to start a CF NBS program may use IRT/IRT algorithms or IRT/DNA algorithms. Those adopting the latter may wish to begin developing projections of positive screen results by using the DNAmutation frequencies identified in the CF Foundation's patient registry and then expanding the data to reflect the population subgroups in that state. Screening algorithms that include class IV and V mutations have been used in recent years, but additional data are needed to determine their appropriate role in CF NBS. As with all 
NBS programs, a balance must be struck between sensitivity, specificity, and clinical utility.

\section{Postscreening Report and Education}

The responsibility for finding and notifying the PCP of the infant with a positive CF screen result is typically that of the state NBS program or its associated maternal and child health bureau, although models exist in which the CF care center or the birth hospital is assigned to this role (Table 4). Because these processes can be very labor intensive, adding a large burden to the reporting system, lines of responsibility and available resources should be well defined before CF NBS implementation.

\section{Positive CF NBS Report}

In keeping with the overall NBS notification and reporting practices, the designated follow-up person from the CF NBS program should identify the PCP, notify that person of the positive screen result, and recommend that the infant be given a sweat test. Ideally, the PCP will be contacted by telephone, followed by timely confirmation of details in writing (eg, fax reports). ${ }^{49}$ The CF NBS follow-up person should be prepared to explain the screening process and the risk of CF for the particular infant and provide contact information for diagnostic evaluation while collecting information as to the likely preferred site for this evaluation. The educational materials that are used to introduce CF NBS (Appendix 1) can be used to refresh and update general information to the health care provider. Other materials, aimed at explaining the CF newborn screen to the public, can be provided to the health care provider to give to the family (Appendix 2).

Family counseling before the sweat test typically begins with the PCP and may or may not be offered again at the CF care center. In the event that the PCP is not comfortable providing this information or is unavailable, the CF care center may need to assume this responsibility. After obtaining a complete family history, the counselor should be able to:

- explain the CF NBS process;

- provide a general description of CF;

- explain the positive CF NBS result and its implications;

- relate the relative risks of a positive, negative, borderline, or insufficient-quantity sweat-test result and risk of a positive or equivocal diagnosis associated with the individual report, including less typical reports such as an ultrahigh IRT level with no identified mutations;

- provide the location of the diagnostic evaluation;

- describe the services (sweat testing, nursing, genetic counseling) and personnel the family can expect to encounter at the diagnostic-evaluation visit;

- form a plan for follow-up of the sweat-test result;

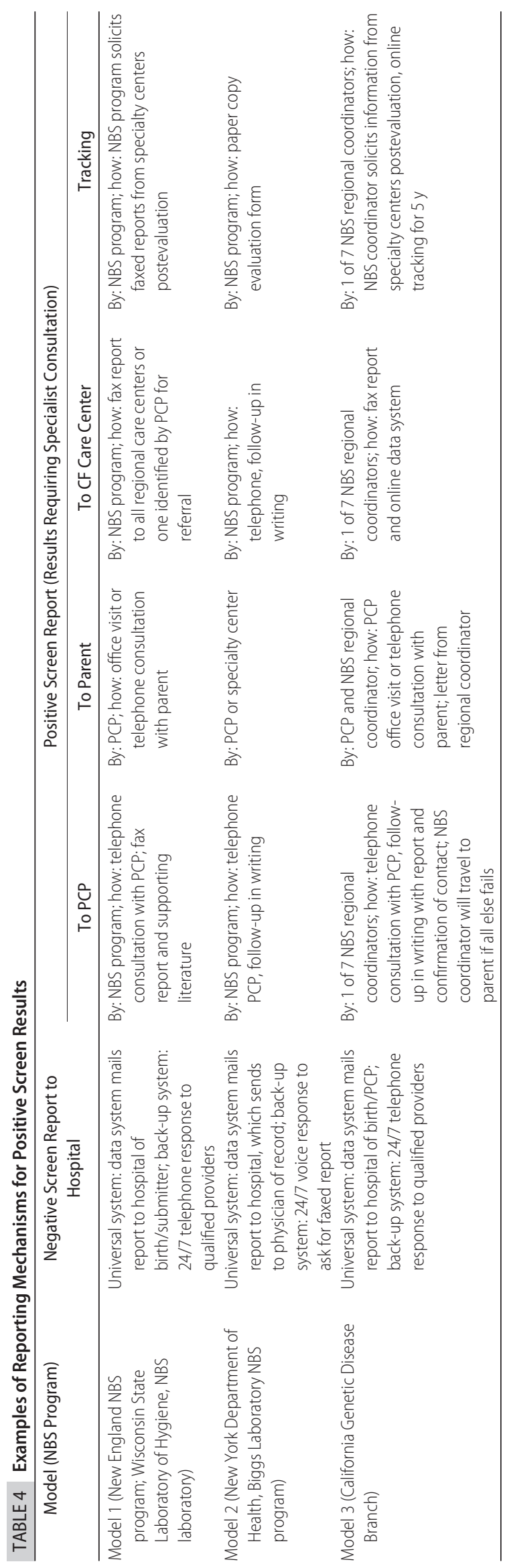


- explain the significance of the presence of a single CFTR mutation, if relevant, for future reproductive decision-making for both the child and other family members, including parents and siblings, ${ }^{30}$ and arrange for testing of the parents and family members if desired; and

- provide educational materials that can answer some of the family's questions.

Once the site for diagnostic testing has been identified, the follow-up person should provide detailed screening reports to the diagnostic site and the genetic counselor, if applicable. Efficient scheduling and communication with the sweat-test laboratory, genetic counselors, and clinicians will be promoted if an individual at the diagnostic center is identified to receive the CF NBS report and coordinate the follow-up evaluation.

\section{Negative CF NBS Report}

A negative result generated by a routine CF NBS may be reported in a manner that is consistent with overall NBS-program practice and in conjunction with routine reporting of other NBS tests. However, if clinical concern has prompted a request for the newborn screen result by the PCP, the CF NBS follow-up person should provide NBS results within the context of recommendations for diagnostic evaluation that are appropriate for each unique set of circumstances. Timely response to such inquiries, especially at the beginning of implementation, helps educate the medical community. Sample fact sheets to accompany the CF NBS report in response to these inquiries are provided in Appendix 3.

\section{Diagnostic Testing of Infants After a Positive CF NBS Result: The Sweat Test}

Confirmatory sweat tests are the gold standard for diagnosis and should be conducted on all infants with a positive NBS result, including those with 2 mutations detected. A positive screen result is not a diagnosis and should always be confirmed by a diagnostic test. Infants with a positive screen result whose mother or father had negative carrier-testing results are at lower risk of having $\mathrm{CF}$, but their elevated IRT value must be investigated by sweat testing.

\section{Sweat-Test Laboratory Qualifications}

The diagnostic quantitative pilocarpine iontophoresis sweat-chloride test should be performed according to the Clinical and Laboratory Standards Institute (CLSI, formerly the National Committee for Clinical Laboratory Standards) guidelines at a College of American Pathologists-accredited laboratory, ${ }^{50}$ as recommended by the $\mathrm{CF}$ Foundation. Optimally, the testing should be performed at a laboratory in affiliation with a CF Foundationaccredited care center, where the test can be coordinated with timely and appropriate genetic counseling and clin- ical follow-up. If the sweat-test result is positive, it is helpful for a CF clinician to be available for immediate intervention. A CF clinician can also help with interpretation of a complex diagnostic profile such as a borderline or negative sweat-test result in the presence of 2 CFTR mutations. Access to a genetic counselor and CF clinician is also helpful if there is a family history of $\mathrm{CF}$, a genotype requiring literature review, or information on sensitive issues such as misattributed paternity. In addition, because infants with CF could be subjected to health care-acquired infection during their diagnostic evaluation or early treatment, ${ }^{23}$ testing and clinical care should take place at sites where this risk is recognized and rigorous CF infection-control guidelines are followed carefully. ${ }^{51}$ Ideally, the sweat test should be available within 2 to 3 hours' driving distance for the family. In regions where greater distances are unavoidable, it may be necessary to establish CLSI guideline-proficient satellite laboratories at which sweat can be both collected and tested or collected and sent to a College of American Pathologists-approved laboratory for analysis. Although not ideal (as shown in one non-US study), 52,53 such arrangements could ensure acceptable testing standards and may prevent long delays in testing as well as provide a safe alternative for situations when long trips are difficult.

\section{Minimum Age and Weight of the Infant for Valid Sweat Testing}

Sweat electrolytes are high on the first day of life, but by the third day they have declined to levels seen outside the newborn period. ${ }^{54}$ The CLSI guidelines permit sweat testing after 48 hours of age. Because CF NBS results are unlikely to be available before 48 hours, the threshold for sweat testing is more likely to be related to weight rather than age; infants weighing $<2 \mathrm{~kg}$ are more likely to provide insufficient sweat for analysis (quantity not sufficient [QNS]).

Other infants are also at increased risk for invalid test results as a result of generation of insufficient sweat. Premature infants or infants who are black exhibit a higher frequency of QNS reports. $43,55,56$ Newer methods of conductance determination on microsamples have been developed but are not yet adequately standardized. Because waiting for the sweat test to be performed leads to family anxiety, ${ }^{37}$ the test should be scheduled as soon as possible and parents should be informed of the risk of QNS. Sweat testing is not considered an emergency, but guidance by a CF specialist should be available for the PCP at all times.

\section{Diagnostic Interpretation After the Sweat Test}

The following guidelines are designed to help CF NBS programs develop follow-up protocols that (1) resolve the outcomes of the vast majority of infants with positive CF NBS results and (2) ensure monitoring of the small 
subset of infants whose diagnostic status cannot be resolved without additional guidance. A planned CF Foundation-sponsored workshop will update the published consensus case definition of $\mathrm{CF}^{57}$ and may provide assistance in addressing some of these diagnostic dilemmas. Regardless, it is most helpful to have specific diagnostic protocols developed by the state CF NBS workgroup in place before implementation so that the lines of action and responsibility are clear.

\section{Positive Sweat-Test Result}

In keeping with CLSI guidelines, sufficient quantities of sweat yielding chloride $\left(\mathrm{Cl}^{-}\right)$values of $\geq 60 \mathrm{mEq} / \mathrm{L}$ is considered diagnostic for $\mathrm{CF} .{ }^{50}$ Exceptions to this rule are familiar to clinicians who practice at CF care centers..$^{58,59}$

\section{Negative Sweat-Test Result}

In the absence of significant clinical concern for $\mathrm{CF}$, a negative sweat-test result $\left(\mathrm{Cl}^{-}\right.$value of $<30 \mathrm{mEq} / \mathrm{L}$ at $<6$ weeks of age) confirms a negative diagnosis. Clinical signs and symptoms consistent with CF or the detection of 2 pathogenic mutations in the CF newborn screen should result in reexamination of the diagnosis by a qualified CF clinician.

\section{Borderline Sweat-Test Result}

In older children and adults, a sweat $\mathrm{Cl}^{-}$value between 40 and $60 \mathrm{mEq} / \mathrm{L}$ has been termed ambiguous or "borderline" and is not clearly diagnostic. However, results from several NBS programs indicate that newborns with CF from 1 to 6 weeks of age tend to have sweat $\mathrm{Cl}^{-}$ levels lower than those found in older infants and children with CF. 55,60 Thus, some screening programs recommend that a lower limit of $30 \mathrm{mEq} / \mathrm{L}$ (still 5 SD above the normal mean ${ }^{61}$ ) be adopted as the lower limit of the borderline range in infants. In Massachusetts, lowering the cutoff from 40 to $30 \mathrm{mEq} / \mathrm{L}$ resulted in an increase from $1.1 \%$ to $3.5 \%$ in the number of screen-positive infants with a borderline sweat-test result, who then required additional monitoring before diagnostic resolution (A.M.C., unpublished data). Evaluation of any infant with a borderline sweat-test result should include repeat sweat testing scheduled for a later date. If 2 CFTR mutations were detected by the newborn screen, a CF specialist should be consulted to determine the appropriate next steps. If 1 CFTR mutation was detected by the screen, a genetic counselor should be consulted to determine if an extended panel of CFTR mutations should be used in additional testing. ${ }^{62}$

For more detailed discussion of recommendations after borderline sweat-test results, see "Diagnostic Dilemmas: Borderline Sweat-Test Results" under "Special Considerations" below.

\section{Communicating Diagnostic-Evaluation Results to the Parents}

CF NBS is optimized by effective communication of diagnostic results, including well-developed counseling and education resources. ${ }^{23,29,30,63-65}$

\section{Positive CF Diagnosis}

When the CF NBS result indicates a high likelihood of $\mathrm{CF}$, the NBS program should alert the clinical care center to allow the parents to meet with a CF clinician at the time of the sweat-test visit. Ideally, the parents of any infant with a positive sweat-test result should be able to meet with a CF clinician before leaving the clinical care center. The CF clinician should be prepared to discuss the diagnosis, prognosis, immediate next steps for the parents, and a short-term plan that includes a visit to meet with the CF team, which will coordinate care with the infant's PCP. Presentation of these recommendations in writing is helpful.

In some cases, particularly at laboratories that experience a low volume of sweat testing, parents will leave before results become available. A report of the diagnosis is then made, ideally, by a CF specialist to the PCP, who will be the primary route of communication to the parents. The PCP should have adequate information (or telephone numbers of relevant CF care centers) to address initial parent concerns and should facilitate the scheduling of a follow-up appointment with the CF team. For families of infants with a positive CF diagnosis, sweat tests should be arranged for all first-degree siblings and for any half-siblings who have signs or symptoms of CF or who have 2 parents known to be carriers.

\section{Negative CF Diagnosis}

As is characteristic of all NBS, most infants with a positive CF NBS result will not have CF. Because families of infants with "false-positive" screen results (in which the screening result is positive and the diagnostic sweat test is negative) will have no continuing support from the CF care center, sympathetic and accurate transmission of information to allay future concerns takes on a high level of importance.

- For a positive screen result that shows no mutations, counseling may be offered by the PCP or the CF care center; no genetic counselor is required. Because the combined screening and diagnostic-test results indicate that the infant is unaffected, with no detected mutation, this counseling should convey the understanding that there is no increased risk of CF but that, as with all children, significant clinical signs should be evaluated. Possible explanations for the elevated IRT level such as low birth weight or Apgar score, prematurity, or race should be discussed.

- For a positive screen result that shows 1 mutation, counseling is optimally offered by a certified genetic counselor or CF clinician. Because the combined 
screening and diagnostic-test results indicate that the infant is an unaffected carrier with at least 1 parent carrying a CF mutation, parent counseling should address the risk to their future pregnancies and whether the parents wish to undertake their own carrier testing. Implications for other family members should also be discussed, and the PCP should be informed that all first-degree siblings who display potential symptoms should have a sweat test performed. The carrier status of the infant should be kept available in the infant's medical chart and, ideally, will be discussed with the individual when reproductive age is reached.

\section{Insufficient Sweat for Analysis (QNS)}

When a diagnosis cannot be made because of insufficient sweat collected, a person must be designated to communicate the QNS result and schedule the follow-up visit. If the parents have already been scheduled for a genetic counseling session during the same visit, the genetic counselor can help explain the report. If the parents have left the center before the QNS report or if genetic counseling was not scheduled, the PCP should be the designated liaison with the family.

\section{Diagnostic Dilemmas}

Ideally, the primary communication of an inconclusive evaluation and its meaning relative to the specific clinical situation is delivered by a CF specialist to the parents. When the PCP must deliver a complex communication, they should facilitate scheduling a follow-up with a CF specialist as indicated by the specialist; families need to be counseled about phenotypic variability associated with specific genotypes ${ }^{66}$ with relevant and accurate information about atypical or complex results.

Ambiguous diagnostic tests, discordant diagnostic tests, or inability to complete diagnostic tests heightens anxiety by prolonging the time to resolution of the positive screening result. In some instances, ambiguous diagnostic-test results may be caused by the presence of a "variant" of CF that places the family in a prolonged period of diagnostic uncertainty without a clear compensating benefit attributable to the screen or the evaluation. ${ }^{60,67,68}$ Ultimately, some of these infants may show classic signs of $\mathrm{CF}$, some may never express disease, and some may develop mild phenotypes (eg, isolated congenital bilateral absence of the vas deferens) so that the interventions prompted by CF NBS might have limited clinical value. Debate continues on the appropriateness of identifying, labeling, following up, or treating infants in the absence of a clear understanding of the prognosis of their particular disorder. Information gained from ongoing experience should help improve decision-making in choosing screening algorithms that meet NBSprogram goals for level of disease to be detected.

\section{Genetic Counseling}

Genetic counseling is a necessary and vital part of follow-up care for parents of children who have a CFTR mutation revealed by a positive CF NBS result. Studies have demonstrated that psychosocial sequelae of falsepositive NBS results can occur, including those resulting from CF-carrier identification. ${ }^{69,70}$ Genetic counseling promotes understanding of the results and offers parents an important venue for psychosocial support and for addressing implications regarding reproductive choices for themselves and other family members. ${ }^{71}$

Some states ensure that parents of screen-positive newborns have access to genetic counseling at CF care centers on the day of the sweat test..$^{29,30}$ Same-day counseling may be provided before sweat testing, while parents await results, or (optimally) after results of the sweat testing are available. However, availability and funding of genetic counseling services varies. Some CF care centers offer genetic counseling on the day of the sweat test, and others inform families that they may speak with a genetic counselor at a later date. ${ }^{72}$ (Note that genetic counselors who practice at a children's hospital should ensure that the parents' PCPs are included in decisions about any parent testing.) Scheduling the genetic counseling with the sweat test ensures transmission of information to the parents and allows knowledgeable caregivers to address the parents' immediate concerns about their child's health and begin to establish a relationship with the family of a child with a positive or borderline sweat-test result. However, trying to coordinate sweat testing together with a genetic counseling appointment may result in some delay. In addition, providing counseling on a subsequent day might result in longer-lasting understanding of the newborn screen results and family risk if the parents' acute anxiety from the sweat test has dissipated. On the other hand, offering genetic counseling on a separate day may result in a lost opportunity for counseling if parents cannot or do not return; $\sim 70 \%$ of families who were offered separate-day genetic counseling in a Massachusetts NBS program never accessed the service. ${ }^{73}$

Providers of genetic counseling related to CF NBS should have training in genetics and experience with caring for patients with CF to ensure that families receive complete care. The family's emotional needs should be addressed in a culturally sensitive manner, ${ }^{74}$ and risk assessment should include available information on families of similar ancestry. ${ }^{75}$ For example, in the families of infants who are identified as CF carriers, a parent who carries the CFTR mutation has been shown to have increased anxiety/guilt as compared with a parent who does not carry a CFTR mutation. ${ }^{31}$ It should be explained that the carrier parent's subsequent pregnancies and those of relatives are at an increased risk for CF, relative to the general population. In a small percentage of cases, both parents are carriers, although the screen- 
positive newborn inherited a mutation from only 1 parent. These couples have a $25 \%$ chance that a previous child has or subsequent child will have CF. Parental CF DNA analysis can be offered to identify the carrier parent and to distinguish the 1 -carrier couple from the 2 -carrier couple. It is important to address this issue sensitively, because parental testing can result in detection of misattributed paternity.

Several states use multiple-mutation panels, which increase the number of carriers identified by the screening process. ${ }^{36}$ The inclusion of alleles (such as $\mathrm{R} 117 \mathrm{H}^{76}$ and $\mathrm{Il}^{4} \mathrm{~T}^{77}$ ) with inadequately understood effects necessitates detailed knowledge by the genetic counseling provider so that parents are properly informed of their child's diagnostic or carrier status and are provided with correct information regarding their chances of having a child with CF in the future.

\section{Quality Assurance of CF NBS: Tracking and Outcomes Assessments}

CF NBS is beneficial only if infants identified by the screen receive a prompt diagnostic evaluation. The responsibility for tracking the infant to assure compliance with the recommendation for evaluation and to document diagnostic outcome is typically that of the state NBS program or its associated maternal and child health bureau. To enable proper data collection and facilitate this tracking, the following must be reported to the state NBS program:

- diagnostic outcome on all NBS-positive infants;

- any CF diagnosis on an individual who was screened by CF NBS regardless of the screening result; and

- any diagnostic result that is discordant with the result of the CF NBS (eg, a negative sweat-test result $[<30$ $\mathrm{mEq} / \mathrm{L}]$ in an infant whose NBS showed 2 severe CF mutations).

- In some models, additional data are collected for longer-term outcomes assessments as a measure of the clinical utility of the overall program. Collection of outcomes data for such purposes constitutes humansubjects research, and protocols should be reviewed by appropriate human-subjects research boards. Outcomes assessments will help quantify the benefits of new approaches or treatments and help detect unanticipated risks such as the early acquisition of Pseudomonas, which occurred in 1 CF NBS trial. ${ }^{23}$ The tracking in that trial resulted in a critical clinical recommendation to isolate newborns with positive CF NBS results from other patients in the CF care center to prevent serious health care-acquired infections. ${ }^{51,78}$

- CF care centers should report sweat and genetic testing results to the state NBS centralized system for cohort analysis, including cases in which CF is diagnosed in children with negative NBS results. False- negative screen results caused by an IRT level below the cutoff value, unidentified CFTR mutations, or human error can occur. In all cases, positive results of sweat tests performed as a result of clinical concern should be reported to the centralized NBS program. This, in turn, facilitates continuing evaluation and modification of screening algorithms and consideration of unanticipated benefits and risks after the implementation of CF NBS.

- The NBS program and the CF care centers need to work carefully as a team to collect the necessary data (Table 5); some data may need to be collected by both groups. It is beneficial for the various care centers in each state to work together to collect statewide information for the ongoing evaluation of the NBS program.

\section{Financing CF NBS and Care}

States fund NBS programs in a variety of ways. ${ }^{79}$ Many states set and collect fees for screening, and many use some public health funding to supplement fees. Specialty care after a diagnosis of CF is made is funded similarly to that for children affected with other disorders.

\section{TABLE 5 Tracking Needed for Evaluation of Follow-up to CF NBS}

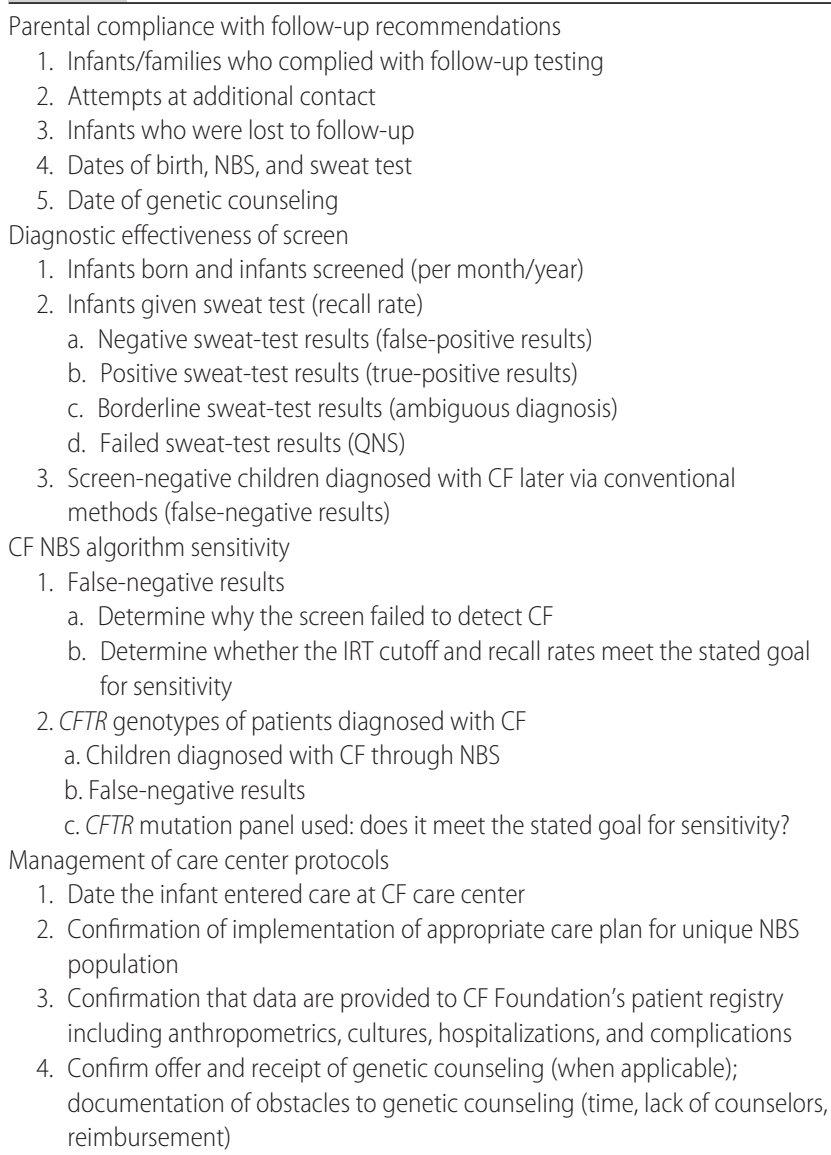


CF care centers must be prepared to receive referrals from the screening program. Care centers and NBSprogram staff should work together, therefore, to predict the number of infants who will screen positive and to outline protocols for their follow-up. In states that use IRT/DNA algorithms, the majority of screen-positive infants who do not have CF will be carriers ${ }^{45}$; before initiating screening, the number of carriers expected should be calculated to identify resources for the parents who should be offered genetic counseling as well. From these estimates, center directors can determine the resources that will be needed for sweat testing, special profile interpretation, genetic counseling, and clinical care for infants who are determined to be affected. ${ }^{80}$

Sweat-testing facilities may see a change in the number of referrals and referral patterns as a result of population-based CF NBS. In Wisconsin, the number of sweat tests ordered decreased after CF NBS implementation, presumably because of a decrease in sweat tests ordered by the PCP for CF-like symptoms; consequently, the number of facilities offering sweat testing was greatly reduced. ${ }^{24}$ In Massachusetts, the number of sweat tests increased when screening began and then diminished somewhat, ${ }^{81}$ although PCPs still order a considerable number of tests. CF care centers and NBS programs should work together to predict the number of sweat tests generated by CF NBS and decide where the tests would be performed to plan for appropriate staffing, while recognizing that sweat-test numbers may vary as the screen is implemented.

Screening algorithms designed to detect the highest number of infants with CF could overload resources available for communication, sweat testing, and counseling. Alternative screening plans may need to be considered if this results in long waits or travel times. Such alternatives might include use of mobile sweat-test laboratories that meet the same standards as those approved by the CF Foundation for standard sweat-test laboratories, quality-controlled local sweat collection that is then sent to a certified laboratory for analysis, a change in screening algorithm, or teleconference counseling.

\section{Research Opportunities}

CF NBS provides the opportunity and the responsibility to conduct research to improve treatment and outcomes in CF (Table 6). Epidemiologic/observational and therapeutic trials should be conducted. Because of the small number of infants diagnosed at each site, research projects will generally require multicenter collaboration, and some studies will require centralized coordination at the NBS-program level. NBS and early diagnosis may accelerate the adoption of new treatments for infants with CF, because it creates an opportunity to define a specific cohort from early in life for entry into clinical trials.

In addition to such clinical research, there must be continual evaluation of outcomes resulting from the initiation of CF NBS (Table 7) based on current clinical practices. This is a crucial step to maintaining highquality CF care for this new population and will also help support the initiation and continuation of CF NBS programs throughout the United States.

\section{Special Considerations}

\section{Community-Customized Mutation Panel}

Ideally, mutation panels for screening should be based on the frequency of alleles present in the regional population. This can vary widely. In California, 50\% of the

TABLE 6 Priorities for Future Research in Those Diagnosed With CF by NBS

\begin{tabular}{|c|c|}
\hline Epidemiologic/Observational & Therapeutic Trials \\
\hline $\begin{array}{l}\text { Risk factors and outcomes associated with acquisition of Pseudomonas } \\
\text { aeruginosa, mucoid P aeruginosa, antibiotic-resistant P aeruginosa } \\
\text { Outcomes associated with S aureus respiratory infection } \\
\text { Temporal association of early respiratory symptoms, Pseudomonas } \\
\text { serology, and respiratory cultures } \\
\text { Role of respiratory viruses in early CF lung disease } \\
\text { Effect of early diagnosis on infants with class IV and V mutations; } \\
\text { benefit/risk assessment } \\
\text { Development of sensitive, easily obtained outcome measures in } \\
\text { infants with CF that correlate with disease progression } \\
\text { High-resolution computed tomography study of lung-disease } \\
\text { progression, exacerbations } \\
\text { Infant pulmonary-function tests } \\
\text { Symptom scoring } \\
\text { Health-related quality-of-life scales } \\
\text { Sweat-testing microtechniques compared to standard testing } \\
\text { approaches } \\
\text { Portable conductance testing compared to sweat Cl- standards for } \\
\text { newborns } \\
\text { Nasal potential difference testing in infants }\end{array}$ & $\begin{array}{l}\text { Early antipseudomonal intervention } \\
\text { Antiinflammatory therapies } \\
\text { Improved nutritional approaches or therapies } \\
\text { Airway-clearance medications/techniques/chest } \\
\quad \text { physiotherapy }\end{array}$ \\
\hline
\end{tabular}




\begin{tabular}{|c|c|}
\hline Action & Outcome Measures \\
\hline Sweat test & $\begin{array}{l}\text { Proportion performed at accredited clinical laboratories } \\
\text { Changes in numbers of sweat tests conducted annually before and after implementation of } \\
\text { state CF NBS } \\
\text { Inconclusive results: number of QNS tests, number of borderline tests, genotype } \\
\text { relationship to sweat-test result }\end{array}$ \\
\hline $\begin{array}{l}\text { Genetic counseling } \\
\text { (when applicable) }\end{array}$ & $\begin{array}{l}\text { Proportion of families of infants with positive screen result/negative sweat-test result (ie, } \\
\text { carriers) receiving genetic counseling } \\
\text { Proportion of families of infants diagnosed with CF through NBS receiving genetic } \\
\text { counseling } \\
\text { Impact on family knowledge and decision-making } \\
\text { Methods for presentation of genetic information to individuals with CF at age } 18 \text { y }\end{array}$ \\
\hline CF care & $\begin{array}{l}\text { Proportion of diagnosed infants followed at CF Foundation-accredited care centers } \\
\text { Outpatient visit frequency } \\
\text { Inpatient hospitalization frequency } \\
\text { Computed tomography score results }\end{array}$ \\
\hline
\end{tabular}

530000 live births are to Hispanic women, largely of Mexican origin, and $6 \%$ are to black women, ${ }^{82}$ whereas Massachusetts has a population that is $8 \%$ Hispanic and $8 \%$ black. ${ }^{83}$ The spectrum of CFTR mutation frequencies varies in populations of each ancestry, and a large proportion of CFTR mutations is still unidentified in Hispanic and black people. A recent study that used a 70 and 86-mutation panel reported a detection rate of $62 \%$ in black infants, 58\% in Hispanic infants, 38\% in Asian infants, and $81 \%$ in Native American infants in the United States compared with $85 \%$ in white infants and $95 \%$ in Ashkenazi Jewish infants. ${ }^{84}$ Identification of infants with CF can be enhanced by choosing an appropriate mutation panel: a $75 \%$ detection rate can be achieved in black populations by screening for 16 "common white" mutations and 8 "common African" mutations. ${ }^{85}$ Differing detection rates are especially significant in states like California, where $33 \%$ of the 70 infants with CF projected to be identified each year without MI are expected to be Hispanic and $2 \%$ are expected to be black. In an attempt to detect at least $90 \%$ of newborns with CF in the 3 main ancestral groups that include Hispanic, non-Hispanic white, and black infants, the California Department of Health Services Genetic Disease Branch has designed a model CF NBS algorithm using a custom mutation panel developed from an analysis of the allele frequency of a cohort of affected patients with CF. ${ }^{86}$ When implemented, results from this screening algorithm will contribute to our understanding of the possible utility of customized population-based mutation panels for CF NBS.

\section{CFTR Mutations and Mild Disease}

The panel of CFTR mutations that the NBS program chooses for screening depends partially on the spectrum of disease that the regional program decides to detect. Because individuals with CF who have one class IV or V mutation would almost always be identified through detection of a class I, II, or III mutation on the other chromosome, ${ }^{87,88}$ some NBS programs may choose not to include class IV or V mutations in the screening panel. Indeed, removal of the class IV $\mathrm{R} 117 \mathrm{H}$ mutation from the Massachusetts CF NBS panel would lower the falsepositive rate by $10 \%$ in that population (A.M.C., unpublished results). However, the proposal to detect infants with CF with a class IV or V mutation by relying on the screen finding a class I, II, or III mutation from the other chromosome also relies on those infants having an elevated sweat $\mathrm{Cl}^{-}$level. Some individuals with class IV and $\mathrm{V}$ mutations can develop clinical symptoms ${ }^{89-93}$ even in the absence of an elevated sweat $\mathrm{Cl}^{-}$concentration.

Use of mutations associated with milder phenotypes may lead to results that are difficult to interpret and communicate in DNA testing of a family after positive NBS results. Because some individuals with a genotype including $\Delta \mathrm{F} 508$ and a class IV or $\mathrm{V}$ mutation may be unaffected by $\mathrm{CF}{ }^{76}$ testing that uses these mutations may best be limited to families of infants who are symptomatic or have a positive sweat-test result.

Complex gene modifiers associated with disease expression of the IVS8-5T mutation (eg, TG repeats and M470V polymorphism) have been identified, ${ }^{94,95}$ but the intricacy of the testing is beyond the current scope of NBS. Furthermore, although up to $20 \%$ of infants with an elevated IRT level, one $\Delta$ F508 mutation, and a sweat $\mathrm{Cl}^{-}$level of $<40 \mathrm{mEq} / \mathrm{L}$ may possess $5 \mathrm{~T}$ on the other chromosome, none have a classic CF phenotype, ${ }^{96}$ which suggests that the IVS8-5T DNA variant, at least, should not be included in mutation panels used for CF NBS.

\section{Diagnostic Dilemmas}

\section{Borderline Sweat-Test Results}

Approximately $10 \%$ of newborns with CF that was detected through NBS using current DNA-mutation panels and diagnosed with CF by a CF clinician express sweat $\mathrm{Cl}^{-}$concentrations $<60 \mathrm{mEq} / \mathrm{L} .{ }^{28}$ Because sweat $\mathrm{Cl}^{-}$levels can change over time, tests resulting in a 
borderline result should be repeated in 1 to 2 months. In the interim, the clinician should monitor nutritional status and growth for any impact by possible pancreatic insufficiency. Also, because individuals with CF and borderline sweat-test results may be susceptible to respiratory disease regardless of pancreatic function, vigilant monitoring for respiratory problems remains critical to enable the early interventions that improve outcome.

A moderate percentage (17\%) of infants with borderline sweat-test results are found to possess 2 CFTR mutations when extended mutation analysis is performed. ${ }^{60}$ Some mutations that occur in the borderline-result group, such as $3849+10 \mathrm{~kb} \mathrm{C} \rightarrow \mathrm{T}$ or A455E, are clearly associated with a disease phenotype, and infants with these mutations should be diagnosed with $\mathrm{CF}$. When $\mathrm{R} 117 \mathrm{H}(7 \mathrm{~T})$ mutation is one of the 2 CFTR mutations, diagnosis is more problematic because only some of the individuals with this genotype develop signs and symptoms of $\mathrm{CF}^{88}$; evaluation of prospective data will help clarify the role of this mutation in NBS. ${ }^{93}$ It may be prudent to defer diagnosis of $\mathrm{CF}$ in these individuals but continue follow-up at a CF care center so that the diagnosis can be made if symptoms appear. Newborns with borderline sweat-test results who have only 1 or no identified CFTR mutation and newborns who have 2 CFTR mutations with sweat $\mathrm{Cl}^{-}$levels $<30 \mathrm{mEq} / \mathrm{L}^{67}$ should be followed up similarly. This situation may be complicated by the lack of commonly accepted protocols for follow-up of infants in these groups. (Normal, borderline, and abnormal sweat-test results with suggested follow-up are discussed in more detail by Parad and Comeau. ${ }^{97}$ )

In the absence of CF NBS, some infants with borderline diagnostic-test results may present later with an atypical CF diagnosis. Individuals with atypical CF tend to present with milder disease at an older age, with lower sweat $\mathrm{Cl}^{-}$levels, pancreatic sufficiency, and mild class IV or $\mathrm{V}$ mutations. These individuals also probably survive longer. However, the natural history of atypical $\mathrm{CF}$ is not well defined, and the early identification of such individuals by NBS may provide much information about the condition over time. Clinical follow-up protocols are not well established for these individuals, and the potential positive impact of CF NBS on atypical CF has not been established. Nevertheless, these infants, once brought to the attention of the CF care community, should be monitored. The follow-up proposed for such infants includes (1) a thorough evaluation by a CF physician, (2) repeat sweat testing, (3) expanded CFTR mutation analysis for all disease-producing mutations (including classes IV and V) if the sweat $\mathrm{Cl}^{-}$level remains elevated, and (4) continued follow-up at a minimum of 1 to 2 visits per year to monitor for any disease development. ${ }^{67}$

\section{Negative Sweat-Test Results}

A sweat-test result that is within the reference range $(<30 \mathrm{mEq} / \mathrm{L})$ may sometimes occur in infants with 2 CFTR mutations that were detected by CF NBS. Because the combined screening and diagnostic-test results require sophisticated analysis to interpret, and because the infant continues to have a high risk of $\mathrm{CF}$, a CF specialist should meet with the family to develop a plan for evaluation and possible treatment, and genetic counseling should be offered. The NBS program must be notified immediately of the discordant result to allow an early opportunity for quality control to ensure the validity of the screening result. Genetic counseling and testing of the parents and extended family may be suggested after acute care issues have been resolved.

Some positive-screened infants with negative sweattest results may be identified to have CF only by later clinical presentations. Clinical follow-up in parallel with repeated sweat testing and extended mutation analysis is the appropriate strategy for resolving the diagnosis in such cases. It may be more cost efficient to perform the full gene-mutation analysis immediately to establish a diagnosis for those in this group, because negative results from a limited analysis would simply prompt a more extensive screen.

\section{ACKNOWLEDGMENTS}

This work was funded by the Cystic Fibrosis Foundation and National Institute of Diabetes and Digestive and Kidney Diseases grant DK61886-01.

Participants in the 2004 Workshop on Implementation of Newborn Screening in Cystic Fibrosis were Frank J. Accurso, MD (University of Colorado, Denver, CO), Mary Ann Baily, PhD (Hastings Center, Garrison, NY), Robert J. Beall, PhD (Cystic Fibrosis Foundation, Bethesda, MD), Drucy Borowitz, MD (State University of New York, Buffalo, NY), C. Michael Bowman, PhD, MD (Medical University of South Carolina, Charleston, SC), Preston W. Campbell, III, MD (Cystic Fibrosis Foundation, Bethesda, MD), Barbara Chatfield, MD (University of Utah, Salt Lake City, UT), Anne Marie Comeau, PhD (University of Massachusetts Medical School, Jamaica Plain, MA), George Cunningham, MD, MPH (California Department of Health Services, Richmond, CA [retired]), Siobhan Dolan, MD, MPH (March of Dimes, White Plains, NY), Philip M. Farrell, MD, PhD (University of Wisconsin, Madison, WI), Sumedha Ghate, MS (St Vincent Hospital, Green Bay, WI), Michael Glass, MS (Washington State Department of Health, Shoreline, WA), Scott Grosse, PhD (Centers for Disease Control and Prevention, Atlanta, GA), Ada Hamosh, MD (Johns Hopkins Hospital, Baltimore, MD), Pamela P. Hawley, MS (Children's Hospital, Boston, MA), Leslie A. Hazle, MS, RN, CPN (Cystic Fibrosis Foundation, Bethesda, MD), Gary Hoffman, BS (Wisconsin State Laboratory of Hygiene, Madison, WI), Martin Kharrazi, PhD, MPH 
(California Department of Health Services, Richmond, CA), Elinor Langfelder-Schwind, MS (St Vincent's Manhattan, New York, NY), Vicky LeGrys, PhD (University of North Carolina, Chapel Hill, NC), John Massie, MBBS, FRACP, PhD (Royal Children's Hospital, Parkville, Australia), Susanna A. McColley, MD (Children's Memorial Hospital, Chicago, IL), Brian P. O'Sullivan, MD (University of Massachusetts Medical Center, Worcester, MA), Richard B. Parad, MD, MPH, University of Massachusetts Medical School, Jamaica Plain, MA), Kenneth A. Pass, PhD, New York State Department of Health, Albany, NY), Suzanne R. Pattee, JD (Cystic Fibrosis Foundation, Bethesda, MD), Darci Pfiel, RN, MS, CPNP (University of Wisconsin Children's Hospital, Madison, WI), Michele A. Puryear, MD, PhD (Health Resources and Services Administration, Rockville, MD), Lynne M. Quittell, MD (Columbia University, New York, NY), Michael J. Rock, MD (University of Wisconsin, Madison, WI), Margaret Rosenfeld, MD, MPH (Children's Hospital and Regional Medical Center, Seattle, WA), Beryl J. Rosenstein, MD (Johns Hopkins Hospital, Baltimore, MD), Lainie F. Ross, MD, PhD (University of Chicago, Chicago, IL), Scott D. Sagel, MD (Children's Hospital, Denver, CO), Lisa Saiman, MD, MPH (Columbia University, New York, NY), Marci Sontag, PhD (Children's Hospital, Denver, CO), Brad Therrell, PhD (National Newborn Screening and Genetics Resource Center, Austin, TX), Monica M. Ulles, RN, PNP, CNS (Massachusetts General Hospital, Boston, MA), Terry White, PhD (Cystic Fibrosis Foundation, Bethesda, MD), and Benjamin Wilfond, MD (National Institutes of Health, Bethesda, MD).

\section{REFERENCES}

1. Lai HJ, Cheng Y, Farrell PM. The survival advantage of cystic fibrosis patients diagnosed through neonatal screening: evidence from the US Cystic Fibrosis Foundation Registry data. J Pediatr. 2005;147(3 suppl):S57-S63

2. McKay KO, Waters DL, Gaskin KJ. The influence of newborn screening for cystic fibrosis on pulmonary outcomes in New South Wales. J Pediatr. 2005; 147(3 suppl):S47-S50

3. Sims EJ, McCormick J, Mehta G, Mehta A. Neonatal screening for cystic fibrosis is beneficial even in the context of modern treatment. J Pediatr. 2005;147(3 suppl):S42-S46

4. Farrell PM, Lai HJ, Li Z, et al. Evidence on improved outcomes with early diagnosis of cystic fibrosis through neonatal screening: enough is enough! J Pediatr. 2005;147(3 suppl): S30-S36

5. Dankert-Roelse JE, Mérelle ME. Review of outcomes of neonatal screening for cystic fibrosis versus non-screening in Europe. J Pediatr. 2005;147(3 suppl):S15-S20

6. Rosenfeld M. Overview of published evidence on outcomes with early diagnosis from large US observational studies. $J \mathrm{Pe}$ diatr. 2005;147(3 suppl):S11-S14

7. Koscik RL, Farrell PM, Kosorok MR, et al. Cognitive function of children with cystic fibrosis: deleterious effect of early malnutrition. Pediatrics. 2004;113:1549-1558

8. Assael BM, Castellani C, Ocampo MB, Iansa P, Callegaro A, Valsecchi MG. Epidemiology and survival analysis of cystic fibrosis in an area of intense neonatal screening over 30 years. Am J Epidemiol. 2002;156:397-401
9. Mastella G, Zanolla L, Castellani C, et al. Neonatal screening for cystic fibrosis: long-term clinical balance. Pancreatology. 2001;1: 531-537

10. Beker LT, Russek-Cohen E, Fink RJ. Stature as a prognostic factor in cystic fibrosis survival. J Am Diet Assoc. 2001;101: 438-442

11. Wang SS, O'Leary LA, Fitzsimmons SC, Khoury MJ. The impact of early cystic fibrosis diagnosis on pulmonary function in children. J Pediatr. 2002;141:804-810

12. Waters DL, Wilcken B, Irwing L, et al. Clinical outcomes of newborn screening for cystic fibrosis. Arch Dis Child Fetal Neonatal Ed. 1999;80:F1-F7

13. Merelle ME, Schouten JP, Gerritsen J, Dankert-Roelse JE. Influence of neonatal screening and centralized treatment on long-term clinical outcome and survival of CF patients. Eur Respir J. 2001;18:306-315

14. Farrell PM, Kosorok MR, Rock MJ, et al. Early diagnosis of cystic fibrosis through neonatal screening prevents severe malnutrition and improves long-term growth. Wisconsin Cystic Fibrosis Neonatal Screening Study Group. Pediatrics. 2001;107: $1-13$

15. Chatfield S, Owen G, Riley HC, et al. Neonatal screening for cystic fibrosis in Wales and the West Midlands: clinical assessment after five years of screening. Arch Dis Child. 1991;66: 29-33

16. Grosse SD, Boyle CA, Botkin JR, et al. Newborn screening for cystic fibrosis: evaluation of benefits and risks and recommendations for state newborn screening programs. MMWR Recomm Rep. 2004;53(RR-13):1-36

17. Accurso FJ, Sontag MK, Wagener JS. Complications associated with symptomatic diagnosis in infants with cystic fibrosis. $J \mathrm{Pe}$ diatr. 2005;147(3 suppl):S37-S41

18. Wilcken B, Chalmers G. Reduced morbidity in patients with cystic fibrosis detected by neonatal screening. Lancet. 1985; 2(8468):1319-1321

19. Siret D, Bretaudeau G, Branger B, et al. Comparing the clinical evolution of cystic fibrosis screened neonatally to that of cystic fibrosis diagnosed through clinical symptoms: a 10-year retrospective study in a French region (Britanny). Pediatr Pulmonol. 2003;35:342-349

20. Koscik RL, Lai HJ, Laxova A, et al. Preventing early, prolonged vitamin E deficiency: an opportunity for better cognitive outcomes via early diagnosis through neonatal screening. $J$ Pediatr. 2005; 147(3 suppl):S51-S56

21. Lai HJ, Cheng Y, Cho H, Kosorok MR, Farrell PM. Association between initial disease presentation, lung disease outcomes, and survival in patients with cystic fibrosis. Am J Epidemiol. 2004; 159:537-546

22. Doull IJ, Ryley HC, Weller P, Goodchild MC. Cystic fibrosisrelated deaths in infancy and the effect of newborn screening. Pediatr Pulmonol. 2001;31:363-366

23. Farrell PM, Li Z, Kosorok MR, et al. Bronchopulmonary disease in children with cystic fibrosis after early or delayed diagnosis. Am J Respir Crit Care Med. 2003;168:1100-1 108

24. Lee DS, Rosenberg MA, Peterson A, et al. Analysis of the costs of diagnosing cystic fibrosis with a newborn screening program. J Pediatr. 2003;142:617-623

25. Massie J, Freezer N, Wilson J, Robertson C. Clinical diagnosis of cystic fibrosis in a screened community: 1989-1998 [abstract]. Pediatr Pulmonol. 2000;(suppl 20):297-298

26. Dankert-Roelse JE, Tijmstra T, Knol K, ten Kate LP. Screening for cystic fibrosis; interviews with parents of children with a false-positive test result [in Dutch]. Ned Tijdschr Geneeskd. 1983; 127:2136-2139

27. Tluczek A, Mischler EH, Farrell PM, Fost N, Peterson NM, Carey P. Parents' knowledge of neonatal screening and re- 
sponse to false-positive cystic fibrosis testing. J Dev Behav Pediatr. 1992;13:181-186

28. Mischler EH, Wilfond BS, Fost N, et al. Cystic fibrosis newborn screening: impact on reproductive behavior and implications for genetic counseling. Pediatrics. 1998;102:44-52

29. Ciske DJ, Haavisto A, Laxova A, Rock LZ, Farrell PM. Genetic counseling and neonatal screening for cystic fibrosis: an assessment of the communication process. Pediatrics. 2001;107: 699-705

30. Wheeler P, Smith R, Dorkin H, Parad R, Comeau A, Bianchi D. Genetic counseling after implementation of statewide cystic fibrosis newborn screening: two years' experience in one medical center. Genet Med. 2001;3:411-415

31. Parad R, Estrella E, Comeau A, Hawley P. Attitude toward CF newborn screening after receiving false positive results: impact of genetic counseling on parents identified as carriers [abstract]. Pediatr Pulmunol. 2004;(suppl 27):226

32. MacCready R. Phenylketonuria screening programs. $N$ Engl J Med. 1963;269:52-53

33. Serving the family from birth to the medical home: a report from the Newborn Screening Task Force convened in Washington DC, May 10-11, 1999. Pediatrics. 2000;106:383-427

34. New England Regional Genetics Group. Position Statement: State Newborn Screening Advisory Committees. Newton, ME: New England Regional Genetics Group; 2000:1-2

35. Whitehead F, Couper R, Moore L, Bourne A, Byard R. Dehydration deaths in infants and young children. Am J Forensic Med Pathol. 1996; 17:73-78

36. Comeau AM, Parad RB, Dorkin HL, et al. Population-based newborn screening for genetic disorders when multiple mutation DNA testing is incorporated: a cystic fibrosis newborn screening model demonstrating increased sensitivity but more carrier detections. Pediatrics. 2004;113:1573-1581

37. Rock MJ, Hoffman G, Laessig RH, Kopish GJ, Litsheim TJ, Farrell PM. Newborn screening for cystic fibrosis in Wisconsin: nine years experience with routine trypsinogen/DNA testing. J Pediatr. 2005;147(3 suppl):S73-S77

38. Sontag MK, Hammond KB, Zielenski J, Wagener JS, Accurso FJ. Two-tiered immunoreactive trypsinogen-based newborn screening for cystic fibrosis in Colorado: screening efficacy and diagnostic outcomes. J Pediatr. 2005;147(3 suppl):S83-S88

39. Crossley JR, Elliott RB, Smith PA. Dried-blood spot screening for cystic fibrosis in the newborn. Lancet. 1979;1(8114): $472-474$

40. Wilfond BS, Gollust SE. Policy issues for expanding newborn screening programs: the cystic fibrosis newborn screening experience in the United States. J Pediatr. 2005;146:668-674

41. Wagener JS, Sontag MK, Accurso F. Newborn screening for cystic fibrosis. Curr Opin Pediatr. 2003;15:309-315

42. Rusakow LS, Abman SH, Sokol RJ, Seltzer W, Hammond K, Accurso FJ. Immunoreactive trypsinogen levels in infants with cystic fibrosis complicated by meconium ileus. Screening. 1993; 2:13-17

43. Rock MJ, Mischler EH, Farrell PM, Bruns WT, Hassemer DJ, Laessig RH. Immunoreactive trypsinogen screening for cystic fibrosis: characterization of infants with a false-positive screening test. Pediatr Pulmonol. 1989;6:42-48

44. Hassemer DJ, Laessig RH, Hoffman GL, Farrell PM. Laboratory quality control issues related to screening newborns for cystic fibrosis using immunoreactive trypsin. Pediatr Pulmonol Suppl. $1991 ; 7: 76-83$

45. Gregg RG, Simantel A, Farrell PM, et al. Newborn screening for cystic fibrosis in Wisconsin: comparison of biochemical and molecular methods. Pediatrics. 1997;99:819-824

46. Sheppard DN, Rich DP, Ostedgaard LS, Gregory RJ, Smith AE, Welsh MJ. Mutations in CFTR associated with mild-disease- form $\mathrm{Cl}^{-}$channels with altered pore properties. Nature. 1993; 362:160-164

47. Braun AT, Farrell PM, Ferec C, et al. Cystic fibrosis mutations and genotype-pulmonary phenotype analysis. $J$ Cyst Fibros. 2006;5:33-41

48. Massie J, Curnow L, Tzanakos N, Francis I, Robertson C. Markedly elevated neonatal immunoreactive trypsinogen levels in the absence of cystic fibrosis gene mutations is not an indication for further testing. Arch Dis Child. 2005;91:222-225

49. Comeau AM, Parad R, Gerstle R, et al. Challenges in implementing a successful newborn CF screening program. J Pediatr. 2005; 147(3 suppl):S89-S93

50. LeGrys VA, Burritt MF, Gibson LE, Hammond KB, Kraft K, Rosenstein BJ. Sweat Testing: Sample Collection and Quantitative Analysis. Approved Guideline. Villanova, PA; National Committee for Clinical Laboratory Standards; 1994. National Committee for Clinical Laboratory Standards document C34-A

51. Saiman L, Siegel J; Cystic Fibrosis Foundation. Infection control recommendations for patients with cystic fibrosis: microbiology, important pathogens and infection control practices to prevent patient-to-patient transmission. Infect Control Hosp Epidemiol. 2003;24(5 suppl):S6-S52

52. Mackay R, George P, Kirk J. Sweat testing for cystic fibrosis: a review of New Zealand laboratories. J Paediatr Child Health. 2006;42:160-164

53. Massie J. Sweat testing for cystic fibrosis: how good is your laboratory? J Paediatr Child Health. 2006;42:153-154

54. Hardy JD, Davison SH, Higgins MU, Polycarpou PN. Sweat tests in the newborn period. Arch Dis Child. 1973;48:316-318

55. Farrell PM, Koscik RE. Sweat chloride concentrations in infants homozygous or heterozygous for F508 cystic fibrosis. Pediatrics. 1996; $97: 524-528$

56. Eng W, LeGrys V, Schechter M, Laughon M, Barker P. Sweat testing in pre-term and full-term infants less than 6 weeks of age. Pediatr Pulmonol. 2005;40:64-67

57. Rosenstein B, Cutting G. The diagnosis of cystic fibrosis: a consensus statement. Cystic Fibrosis Foundation Consensus Panel. J Pediatr. 1998;132:589-595

58. Rosenstein BJ, Langbaum TS. Misdiagnosis of cystic fibrosis: need for continuing follow-up and reevaluation. Clin Pediatr (Phila). 1987;26:78-82

59. Rosenstein BJ, Langbaum TS, Gordes E, Brusilow SW. Cystic fibrosis: problems encountered with sweat testing. JAMA. 1978;240:1987-1988

60. Parad RB, Comeau AM, Dorkin HL, et al. Sweat testing newborn infants detected by cystic fibrosis newborn screening. J Pediatr. 2005;147(3 suppl):S69-S72

61. Padoan R, Bassotti A, Seia M, Corbetta C. Negative sweat test in hypertrypsinaemic infants with cystic fibrosis carrying rare CFTR mutations. Eur J Pediatr. 2002;161:212-215

62. Desmarquest P, Feldmann D, Tamalat A, et al. Genotype analysis and phenotypic manifestations of children with intermediate sweat chloride test results. Chest. 2000;118:1591-1597

63. Parsons EP, Clarke AJ, Bradley DM. Implications of carrier identification in newborn screening for cystic fibrosis. Arch Dis Child Fetal Neonatal Ed. 2003;88:F467-F471

64. Dillard J, Carson C, Bernard C, Laxova A, Farrell PM. An analysis of communication following newborn screening for cystic fibrosis. Health Commun. 2004; 16:197-205

65. Ahmed N, Corey M, Forstner G, et al. Molecular consequences of cystic fibrosis transmembrane regulator (CFTR) gene mutations in the exocrine pancreas. Gut. 2003;52:1159-1164

66. McKone EF, Emerson SS, Edwards KL, Aitken ML. Effect of genotype on phenotype and mortality in cystic fibrosis: a retrospective cohort study. Lancet. 2003;361:1671-1676

67. Parad RB, Comeau AM. Diagnostic dilemmas resulting from 
the immunoreactive trypsinogen/DNA cystic fibrosis newborn screening algorithm. J Pediatr. 2005;147(3 suppl):S78-S82

68. Wilfond BS, Parad RB, Fost N. Balancing benefits and risks for cystic fibrosis newborn screening: implications for policy decisions. J Pediatr. 2005;147(3 suppl):S109-S113

69. Parsons E, Bradley D. Psychosocial issues in newborn screening for cystic fibrosis. Paediatr Respir Rev. 2003;4:285-292

70. Super M. Cystic fibrosis newborn screening and detection of carriers. Arch Dis Child Fetal Neonatal Ed. 2003;88:F448-F449

71. National Society of Genetic Counselors. Genetic counseling as a profession. 2005. Available at: www.nsgc.org/about/ definition.cfm. Accessed June 27, 2006

72. Langfelder-Schwind E, Rosenblatt MJ, Caine E, et al. Genetic counseling follow up for parents of CF gene mutation carriers identified through newborn screening in New York State. Pediatr Pulmonol. 2003; (suppl 25):224

73. Comeau AM, Parad R, Gerstle R, et al. Communications systems and their models: Massachusetts parent compliance with recommended specialty care following positive CF newborn screen. J Pediatr. 2005;147(3 suppl):S98-S100

74. Weil J. Psychosocial genetic counseling in the post-nondirective era: a point of view. J Genet Couns. 2003;12:199-211

75. Grody WW, Cutting GR, Klinger KW, et al. Laboratory standards and guidelines for population-based cystic fibrosis carrier screening. Genet Med. 2001;3:149-154

76. Curnow L, Savarirayan R, Massie J. Genetic counseling after carrier detection by newborn screening when one parent carries DeltaF508 and the other R117H. Arch Dis Child. 2003;88: $886-888$

77. Rohlfs EM, Zhou Z, Sugarman EA, et al. The I148T CFTR allele occurs on multiple haplotypes: a complex allele is associated with cystic fibrosis. Genet Med. 2002;4:319-323

78. Saiman L, Siegel J. Infection control in cystic fibrosis. Clin Microbiol Rev. 2004;17:57-71

79. Watson MS, Doyle DL, Johnson KA. Financing genetics and newborn screening services archive [Webcast]. 2005. Available at: www.mchcom.com/archivedWebcastDetailNewInterface. asp?aeid $=337$. Accessed June 27, 2006

80. Wilcken B, Wiley V, Sherry G, Bayliss U. Neonatal screening for cystic fibrosis: a comparison of two strategies for case detection in 1.2 million babies. J Pediatr. 1995;127:965-970

81. Parad R, Comeau AM, Eaton R, et al. Impact of CF newborn screening on pediatrician's decision to sweat test screened infants with CF-like symptoms. Paper presented at: 14th National Neonatal Screening Symposium; St Louis, MO; September 7-10, 1999

82. California Department of Health Services, Center for Health Statistics Vital Query System. Birth records 2003. Available at: www.applications.dhs.ca.gov/vsq/default.asp. Accessed June 27, 2006

83. US Census Bureau, Population Division. Population estimates by state: annual estimates of the population by sex, race, and Hispanic or Latino origin for states: April 1, 2000 to July 1, 2004. 2005. Available at: www.census.gov/popest/states/asrh/ SC-EST2004-03.html. Accessed June 27, 2006
84. Heim R, Sugarman E, Allitto B. Improved detection of cystic fibrosis mutations in the heterogeneous U.S. population using an expanded, pan-ethnic mutation panel. Genet Med. 2001;3: $168-176$

85. Macek MJ, Mackova A, Hamosh A, et al. Identification of common cystic fibrosis mutations in African-Americans with cystic fibrosis increases the detection rate to $75 \%$. Am J Hum Genet. 1997;60:1122-1127

86. Alper OM, Wong LJ, Young S, et al. Identification of novel and rare mutations in California Hispanic and African American cystic fibrosis patients [published correction appears in Hum Mutat. 2005;25:223]. Hum Mutat. 2004;24:353

87. Massie J, Clements B. Diagnosis of cystic fibrosis after newborn screening: the Australasian experience-twenty years and five million babies later: a consensus statement from the Australasian Pediatric Respiratory Group. Pediatr Pulmonol. 2005;39: $440-446$

88. Massie RJ, Poplawski N, Wilcken B, Goldblatt J, Byrnes C, Robertson C. Intron-8 polythymidine sequence in Australasian individuals with CF mutations R117H and R117C. Eur Respir J. 2001;17:1195-1200

89. Augarten A, Kerem BS, Yahav Y, et al. Mild cystic fibrosis and normal or borderline sweat test in patients with the $3849+10$ kb C > T mutation. Lancet. 1993;342:25-26

90. Gan KH, Veeze HJ, van den Ouweland AM, et al. A cystic fibrosis mutation associated with mild lung disease. $N$ Engl J Med. 1995;333:95-99

91. Highsmith WE, Burch LH, Zhou Z, et al. A novel mutation in the cystic fibrosis gene in patients with pulmonary disease but normal sweat chloride concentrations. N Engl J Med. 1994;331: 974-980

92. Kiesewetter S, Macek M Jr, Davis C, et al. A mutation in CFTR produces different phenotypes depending on chromosomal background. Nat Genet. 1993;5:274-278

93. Parad R, Comeau A, Soultan Z, et al. Outcomes from a cohort of immunoreactive trypsinogen (IRT)/DNA cystic fibrosis newborn screen (CFNBS) positive infants who have R117H as one of two detected CFTR mutations: worrisome oropharyngeal cultures in infants with sweat chloride levels $\left[\mathrm{Cl}^{-}\right]<30 \mathrm{meq} / \mathrm{L}$ [abstract]. Pediatr Pulmonol. 2005;(suppl 28):256

94. Groman JD, Hefferon TW, Casals T, et al. Variation in a repeat sequence determines whether a common variant of the cystic fibrosis transmembrane conductance regulator gene is pathogenic or benign. Am J Hum Genet. 2004;74:176-179

95. Cuppens H, Lin W, Jaspers M, et al. Polyvariant mutant cystic fibrosis transmembrane conductance regulator genes: the polymorphic $(\mathrm{Tg}) \mathrm{m}$ locus explains the partial penetrance of the T5 polymorphism as a disease mutation. J Clin Invest. 1998;101: 487-496

96. Massie RJ, Wilcken B, Van Asperen P, et al. Pancreatic function and extended mutation analysis in DeltaF508 heterozygous infants with an elevated immunoreactive trypsinogen but normal sweat electrolyte levels. J Pediatr. 2000;137:214-220

97. Parad RB, Comeau AM. Newborn screening for cystic fibrosis. Pediatr Ann. 2003;32:528-535 
To: Providers of care to newborns

(with "out of range" CF newborn screening results)

From: New England Newborn Screening Program (NENSP)

names

Massachusetts CF Center Directors and representatives

names

\section{Re: Cystic Fibrosis (CF) Newborn Screening}

Date:

Effective $\boldsymbol{D A T E}$, the Newborn Screening services that are offered to every infant born in Massachusetts includes the option of screening for early indicators of Cystic Fibrosis (CF). For the duration of time that CF newborn screening is offered as a pilot program per Department of Public Health regulations, parents of newborns will have the option to decline CF screening. Current experience shows that $98 \%$ of parents consent.

This letter includes the following information:

- Basic facts about $\mathrm{CF}$

- Components of the NENSP CF newborn screening program

\section{Enclosures to include when using letter to support "out of range” report \\ - "Action Sheet" for Primary Care Physician \\ - Information Sheet "For Parents and Families" \\ - Sweat Test Scheduling Information}




\section{Basic Facts about Cystic Fibrosis (CF)}

- $\mathrm{CF}$ is the most common disorder of autosomal recessive inheritance in Caucasians.

- In general, it occurs in 1/3000 Caucasian, 1/6000 Hispanic, 1/10,000 AfricanAmerican, and 1/90,000 Asian-American births.

- Only $15 \%$ of CF patients have neonatal clinical presentation with bowel obstruction (most commonly meconium ileus). Note that $80-90 \%$ of infants presenting with meconium ileus have $\mathrm{CF}$.

- Of the remaining $85 \%$ of CF patients, without NBS $50 \%$ are diagnosed by 14 months.

- In Massachusetts, $80 \%$ of all CF patients are diagnosed by age 5 years without NBS.

- The most common presenting symptoms are malabsorption diarrhea (due to pancreatic insufficiency) and failure to thrive, recurrent and chronic pulmonary problems, or a combination of both.

- CF pathophysiology is due to Cystic Fibrosis Transmembrane Conductance Regulator (CFTR) gene mutations (over 1,400 reported). The most common mutation is $\triangle \mathrm{F} 508$. Abnormal CFTR protein disrupts chloride transport and water movement across secretory epithelial membranes.

- Abnormal secretions in pancreatic ducts, airways, intestines and vas deferens lead to blocked lumens, organ injury and dysfunction.

- Abnormal lung secretions lead to chronic respiratory tract infections with S. aureus and $P$. aeruginosa

- High sweat chloride concentration ( $\geq 60 \mathrm{mEq} / \mathrm{L})$ results from abnormal epithelial cells in sweat glands. Pilocarpine iontophoresis (Sweat Test) is the gold standard for diagnosis. DNA testing that reveals two CFTR mutations is also diagnostic.

In recent years, pediatric health care providers have done well in identifying CF patients for initiation of appropriate therapy. Recent data have suggested that newborn screening for $\mathrm{CF}$ (which results in early detection for the $85 \%$ of affected babies who do not have bowel obstruction) can lead to avoidance of malnutrition and improved height and weight. Although the potential for improved pulmonary outcome and increased longevity are suggested by early data, the conclusive results from these ongoing studies are not yet available. In your state, newborn screening is projected to identify about \# CF-affected infants each year.

See also state specific reference material

See also Centers for Disease Control and Prevention. Newborn screening for cystic fibrosis: evaluation of benefits and risks and recommendations for state newborn screening programs. MMWR Recomm Rep. 2004; 53(RR-13)1-36. 


\section{Components of the NENSP CF Newborn Screening Program}

\section{The CF newborn screen may include up to three components: ${ }^{\mathrm{a}}$}

1. Level of serum trypsinogen (IRT), a pancreatic enzyme that is elevated in the serum of most CF-affected newborns. Samples with values above the $95^{\text {th }}$ percentile will proceed to DNA assay (part 2).

2. DNA assay, for detection of any of \# common CFTR gene mutations and when appropriate, \# DNA variants. Detection of one or more of CFTR mutations or an IRT $>99.9^{\text {th }}$ percentile will result in newborns being referred for sweat testing at a CFF Center (part 3)

3. Sweat Test (Pilocarpine iontophoresis), for determination of sweat chloride concentration. Sweat chloride concentration $\geq 60 \mathrm{mEq} / \mathrm{L}$ suggests a diagnosis of $\mathrm{CF}$. Borderline results $(30-59 \mathrm{mEq} / \mathrm{L})$ or inadequate sweat quantity for analysis (QNS) may prompt repeat testing.

The NENSP brochure, Answers to common questions about newborn screening (available in 9 languages), describes information about all disorders included in newborn screening, and details the CF newborn screening pilot program for parents. This information is also available on the Program's web site (www.umassmed.edu/nbs/).

\section{Expected number of referrals and case detections}

(estimates based on $100 \%$ participation)

- Each day, \# screened baby will be referred for sweat testing (\# babies/year)

- Each year, \#-\# babies with CF will be identified

- A baby referred with a POSITIVE screening result has a 1/\# chance of having CF (risk is category dependent: see below)

\section{Limitations of CF Newborn Screening}

CF newborn screening has limitations. Keep in mind that this screening algorithm is not a diagnostic test. No screening algorithm is perfect in its ability to detect all affected individuals while also producing no false positive results.

1.) CF screening is not mandated, so the parents may have declined testing

2.) We anticipate that $1 \mathrm{CF}$ affected baby per year may not be detected by this screen (i.e., would have a FALSE NEGATIVE CF newborn screening result) and will present later in life with CF symptoms. A sweat test remains clinically indicated for evaluation of any child with symptoms suspicious for CF. Clinicians at the NENSP and CF centers will remain available to consult on such clinical scenarios.

\footnotetext{
${ }^{\text {a }}$ Alternative: description of IRT/IRT algorithm.

${ }^{\text {b }}$ Specify your state's program
} 


\section{New England Newborn Screening Program \\ ACTION SHEET \\ for Primary Care Provider}

INTERPRETATION OF NEWBORN SCREENING REPORT:

Your patient has a positive (out of range) CF newborn screening result.

This result means that the infant is at increased risk for Cystic Fibrosis (CF). The specific risk is dependent on the exact category of positive screen as indicated below.

- Category $\boldsymbol{C}$ : IRT $>95^{\text {th }}$ percentile and two mutations were detected. The infant most likely has $\mathrm{CF}$.

- Category B: IRT $>95^{\text {th }}$ percentile and one mutation was detected. The infant has about a $1 / 30$ chance of CF. Infants with Category B results who are then shown to have CF have a second mutation that is not included in the screen. Infants with Category $\mathrm{B}$ results whose diagnostic test shows them to be unaffected are carriers.

- Category A: IRT $>99.9$ th percentile and no mutations detected. The infant has a $<1 / 100$ chance of CF. Because the infant's IRT result is so high, it's possible that the infant may be affected with two CFTR mutations that are not included in our screen. Perinatal stresses can also cause high IRT levels.

\section{RECOMMENDED NEXT STEPS BY PRIMARY CARE PHYSICIAN:}

- Contact family. Report positive newborn screening result and refer infant for diagnostic sweat test (with parent genetic counseling if a mutation was detected)

- Contact CF Center. Schedule sweat test; when scheduling, indicate that the referral is because of a positive newborn screening result.

Note: There is no age-specific criterion for sweat testing. Ideally, infants will have attained a weight of 2 kilograms prior to the sweat test. The likelihood that the sweat test result on a young infant will be complete is very good. Insufficient sweat for analysis (QNS) rates vary by center but in general, more than $90 \%$ infants should have valid test results after one visit.

If you have any questions or need further assistance, please contact the New England Newborn Screening Program at 617-983-6300. 
My Baby had a positive CF Newborn Screening Test

What is CF Newborn Screening? CF newborn screening tests help to find babies who might have cystic fibrosis. Most babies with positive newborn screening tests do not have CF. Babies who do have CF and who are found early can be treated early.

What does my baby's positive CF newborn screening test mean? It means that your baby needs a special test so that you can know if your baby has CF. The special test is called a sweat test.

Where do I get a sweat test for my baby? We recommend that experts at a CF Center do the sweat testing. At a CF Center, staff members know how to do the test on young babies. In addition, there will be support staff at the Center who may be able to provide you with genetic counseling about your baby's CF newborn screening test or who will be able to help if the sweat test result is not clear.

I had a negative CF blood test when I was pregnant. Does my baby still need a sweat test? Yes. Any baby whose newborn screening result is positive should have a sweat test.

How is the sweat test done? The sweat test is simple and should not hurt your baby. If you yourself had a sweat test, your skin might feel warm and tingly for about five minutes during the test. Before the test, the technician will apply a chemical that causes sweating to a small area on your baby's arm or leg. Then, an electrode is attached to stimulate a weak electrical current. Your baby's sweat is collected on a piece of filter paper or in a plastic coil. The collected sweat is then sent to the lab and tested. It takes about one hour from start to finish.

Do I need to do anything to prepare my baby for the sweat test? Do not use any lotions or creams on your baby's arms or legs on the day of the test. Any regular medications may be continued and will have no effect on the test results. Because clinic rooms can be chilly, bring an extra blanket or sweater and hat to help keep your baby warm during the test.

How will I know the results of the sweat test? That depends on how the CF Center works. At some Centers, sweat test results are phoned to your baby's doctor at the end of the day and the your baby's doctor will contact you. At other Centers, you may have a genetic counseling appointment before you leave and sometimes the genetic counselor will report the results to you. You can ask ahead of time so that you know what to expect.

When I have the results of my baby's sweat test, will I know if my baby has CF? Most of the time the results of your baby's sweat test will clearly tell you whether your baby has $\mathrm{CF}$ or not. Sometimes, the sweat test will have to be repeated.

APPENDIX 2

Information for parents of an infant with a positive CF NBS result. 


\section{INTERPRETATION OF \\ Cystic Fibrosis Newborn Screening Results \\ IN RESPONSE TO CLINICAL CONCERN}

\section{1. "In Range" results reported to you in a single mailing:}

Targeted congenital disorder/Analyte Tested Cystic Fibrosis/CF Percentile

Results Within Range

a $\%$ that is $\leq 95$

Interpretation: No DNA testing was prompted by the immunoreactive trypsinogen (IRT) result; the IRT level was $\leq 95^{\text {th }}$ percentile. This in-range screening result has a negative predictive value of 99.99\% for cystic fibrosis. Note that any baby with this result still has at least a 1/50 chance of being a CF carrier.

\section{2. "IN RANGE" results reported to you in a second mailing:}

First mailing's result:

Targeted congenital disorder/Analyte Tested Results Within Range Results Out of Range

Cystic Fibrosis/CF Percentile

$\sim$ PENDING - FINAL REPORT WILL FOLLOW

Second mailing's result:

Targeted congenital disorder/Analyte Tested $\quad$ Results Within Range Results Out of Range

Cystic Fibrosis Screen

IN RANGE

Interpretation: DNA testing was performed on this specimen and no mutations were detected from our panel of common mutations. In addition, though the immunoreactive trypsinogen (IRT) was > $95^{\text {th }}$ percentile, it did not meet our criteria for recommending a sweat test in the absence of observed mutations. The negative predictive value of this test is very high. However, because we do not screen for all of the $>1000$ mutations currently reported in the CFTR gene, there remains a very small possibility that this baby carries one or more mutations that are not included in our panel of common CFTR mutations.

\section{3. "CF SCREEN POSITIVE" results.}

All positive CF Newborn screening results will be phone reported to the infant's healthcare provider. The phone consult will be followed by a faxed report of findings.

\section{ACTIONS:}

- CF Screen positive results: we will recommend that the infant undergo a confirmatory sweat test.

- "IN RANGE" results: In range results are considered normal, and our Program recommends no further action. HOWEVER, we remind clinicians that the CF newborn screening algorithm is not a diagnostic test, and will NOT detect all CF-affected infants. IF YOU HAVE PERSISTENT CLINICAL CONCERNS that could be consistent with CF, such as poor weight gain, malabsorption stools, recurrent respiratory tract infections, recurrent respiratory symptoms such as cough or wheezing, or if you have information that both parents are carriers of CF mutations, we encourage you to consider a sweat test, which is still considered the gold standard.

We would be pleased to discuss these results and any concerns about their interpretation with you. 


\section{Guidelines for Implementation of Cystic Fibrosis Newborn Screening Programs: Cystic Fibrosis Foundation Workshop Report}

Anne Marie Comeau, Frank J. Accurso, Terry B. White, Preston W. Campbell, III, Gary Hoffman, Richard B. Parad, Benjamin S. Wilfond, Margaret Rosenfeld, Marci K. Sontag, John Massie, Philip M. Farrell and Brian P. O'Sullivan

Pediatrics 2007;119; e495-e518

DOI: $10.1542 / p e d s .2006-1993$

\section{Updated Information \\ \& Services}

References

Citations

Subspecialty Collections

Permissions \& Licensing

Reprints including high-resolution figures, can be found at: http://www.pediatrics.org/cgi/content/full/119/2/e495

This article cites 90 articles, 24 of which you can access for free at:

http://www.pediatrics.org/cgi/content/full/119/2/e495\#BIBL

This article has been cited by 2 HighWire-hosted articles: http://www.pediatrics.org/cgi/content/full/119/2/e495\#otherarticl es

This article, along with others on similar topics, appears in the following collection(s):

\section{Respiratory Tract}

http://www.pediatrics.org/cgi/collection/respiratory_tract

Information about reproducing this article in parts (figures, tables) or in its entirety can be found online at: http://www.pediatrics.org/misc/Permissions.shtml

Information about ordering reprints can be found online: http://www.pediatrics.org/misc/reprints.shtml 